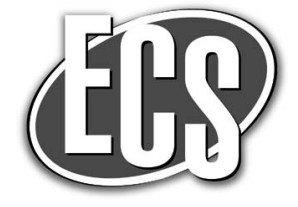

\title{
Oxygen Reduction Reaction Measurements on Platinum Electrocatalysts Utilizing Rotating Disk Electrode Technique
}

\section{Impact of Impurities, Measurement Protocols and Applied Corrections}

\author{
Kazuma Shinozaki, ${ }^{a, b, c, *, z}$ Jason W. Zack, ${ }^{a}$ Ryan M. Richards, ${ }^{\text {b }}$ Bryan S. Pivovar, ${ }^{\text {a,*** }}$ \\ and Shyam S. Kocha ${ }^{\mathrm{a}, *, \mathrm{z}}$
}

\author{
${ }^{a}$ National Renewable Energy Laboratory, Golden, Colorado 80401, USA \\ ${ }^{b}$ Colorado School of Mines - Department of Chemistry, Golden, Colorado 80401, USA \\ ${ }^{c}$ Toyota Central R\&D Labs., Inc., Nagakute, Aichi 480-1192 Japan
}

\begin{abstract}
The rotating disk electrode (RDE) technique is being extensively used as a screening tool to estimate the activity of novel PEMFC electrocatalysts synthesized in lab-scale (mg) quantities. Discrepancies in measured activity attributable to glassware and electrolyte impurity levels, as well as conditioning, protocols and corrections are prevalent in the literature. The electrochemical response to a broad spectrum of commercially sourced perchloric acid and the effect of acid molarity on impurity levels and solution resistance were also assessed. Our findings reveal that an area specific activity (SA) exceeding $2.0 \mathrm{~mA} / \mathrm{cm}^{2}\left(20 \mathrm{mV} / \mathrm{s}, 25^{\circ} \mathrm{C}, 100 \mathrm{kPa}, 0.1 \mathrm{M}\right.$ $\mathrm{HClO}_{4}$ ) for polished poly-Pt is an indicator of impurity levels that do not impede the accurate measurement of the ORR activity of Pt based catalysts. After exploring various conditioning protocols to approach maximum utilization of the electrochemical area (ECA) and peak ORR activity without introducing catalyst degradation, an investigation of measurement protocols for ECA and ORR activity was conducted. Down-selected protocols were based on the criteria of reproducibility, duration of experiments, impurity effects and magnitude of pseudo-capacitive background correction. Statistical reproducibility of ORR activity for poly-Pt and $\mathrm{Pt}$ supported on high surface area carbon was demonstrated.

(C) The Author(s) 2015. Published by ECS. This is an open access article distributed under the terms of the Creative Commons Attribution 4.0 License (CC BY, http://creativecommons.org/licenses/by/4.0/), which permits unrestricted reuse of the work in any medium, provided the original work is properly cited. [DOI: 10.1149/2.1071509jes] All rights reserved.
\end{abstract}

Manuscript submitted June 1, 2015; revised manuscript received June 29, 2015. Published July 22, 2015. This was Paper 1239 presented at the San Francisco, California, Meeting of the Society, October 27-November 1, 2013.

Although the commercialization of automotive proton exchange membrane fuel cells (PEMFCs) is imminent, an additional reduction in cathode platinum electrocatalyst loading is being pursued to meet residual cost targets. Currently $\sim 30 \mathrm{~g}$ of $\mathrm{Pt}$ dispersed on carbon black is required to produce a net power output of $\sim 100 \mathrm{~kW}$ in automotive fuel cell stacks $\left(\sim \$ 50 / \mathrm{g}_{\mathrm{Pt}} ; \$ 1500\right.$ per $100 \mathrm{~kW}$ stack $) .{ }^{1-3}$ In order to eliminate any concerns related to the availability of Pt resources, the consensus target for total Pt loading is $\sim 0.1 \mathrm{~g}_{\mathrm{Pt}} / \mathrm{kW}$ and is roughly based on the current utilization estimates of platinum in catalytic convertors of gasoline powered vehicles. To achieve the target $\mathrm{Pt}$ loading, researchers around the world are engaged in synthesizing novel ORR electrocatalysts that promise an activity improvement of a factor of $\sim 4$. These laboratory-scale electrocatalysts are synthesized in extremely small quantities of tens of $\mu \mathrm{g}$ and demand rapid screening for ORR activity prior to scale-up and subsequent in-situ evaluation in subscale fuel cells $\left(5-50 \mathrm{~cm}^{2}\right)$. As a result, half-cell electrochemical techniques are attracting considerable attention as a high throughput research platform and are demonstrating increased sophistication due to advancements in test methodologies.

A number of half-cell electrochemical techniques have been developed over the years and may be divided into two classes: those designed to facilitate large limiting currents and others that perturb and control finite limiting currents. In the case of practical fuel cells, (differential cells tested under high stoichiometry of oxygen) the limiting currents are assumed to be high enough that the measured currents at high potentials around $\sim 0.9 \mathrm{~V}$ (corrected for resistive losses) may be treated as kinetic currents and correction for oxygen mass transport is considered unnecessary. ${ }^{4}$ The floating electrode ${ }^{5}$ and gasphase/wall-jet electrode ${ }^{6}$ half-cell methods have limiting current that are large compared to raw currents and may be approximated as kinetic currents that fall under the first classification. In these types of electrodes, $\mathrm{O}_{2}$ diffusion to the catalyst surface may be modeled as depicted in Fig. 1a, where $\mathrm{O}_{2}$ diffuses through thin (nm scale) ionomer or solution film to obtain large $\mathrm{O}_{2}$ flux/limiting current. Conversely, hydrodynamic methods such as channel flow dual electrode

\footnotetext{
*Electrochemical Society Student Member.

**Electrochemical Society Active Member.

${ }^{\text {zE}}$-mail: shinozaki@mosk.tytlabs.co.jp; shyam.kocha@nrel.gov
}

$(\mathrm{CFDE}),{ }^{7,8}$ rotating disk electrode and rotating ring disk electrodes (RDE or RRDE) ${ }^{9}$ methods operate on the principle of controllable limiting currents and fall under the second classification. In these cases, $\mathrm{O}_{2}$ diffusion to catalyst surface may be modeled as illustrated in Fig. 1b, where $\mathrm{O}_{2}$ diffuses through a thick $(>10 \mu \mathrm{m})$ boundary layer in electrolyte solution (with an optional Nafion film) to obtain finite but well-controlled $\mathrm{O}_{2}$ flux/limiting currents. In hydrodynamic methods, kinetic currents may be extracted from the measured raw currents at high potentials by the application of the Koutecký-Levich (K-L) equation. ${ }^{9}$

Assuming a simple model as shown in Fig. 1, the K-L equation may be expressed as:

$$
\frac{1}{i}=\frac{1}{i_{\mathrm{k}}}+\frac{1}{i_{\mathrm{d}}}+\frac{1}{i_{\mathrm{f}}}
$$

where $i$ is the raw current, $i_{\mathrm{k}}$ is the kinetic current, $i_{\mathrm{d}}$ is the $\mathrm{O}_{2}$ diffusionlimited current (Fig. 1a) in the gas phase or (Fig. 1b) through the bulk electrolyte, and $i_{\mathrm{f}}$ is the $\mathrm{O}_{2}$ diffusion-limited current through (Fig. 1a, 1b) the ionomer film or (Fig. 1a) a thin electrolyte layer. ${ }^{10}$

Although floating electrode and CFDE half-cell techniques have strengths that make them worthy of being pursued and refined, the RDE technique appears to be overwhelmingly advantageous in its present state-of-development. In fact, despite the issues of inconsistencies in measured ORR activity between labs (discussed in this paper), the RDE technique is the most popular and preferred method for a majority of fuel cell electrochemists. In part, this is due to the commercial availability of rotators and associated components such as standardized disks of glassy carbon (GC), gold, platinum, copper, etc., at a reasonable cost. Materials such as single crystal Pt and Pt alloys can be custom made to provide model surfaces that are tremendously useful for conducting fundamental studies. Additionally, once a standard protocol and a strong baseline has been established, sample throughput is fairly high; a novel high surface area Pt-based catalyst can be screened for electrochemical activity by preparing $1-2$ inks $/ 4-8$ electrodes in 1-2 days by a single operator.

Papers published prior to the 1980 s routinely discuss studies on $\mathrm{Pt}$ wires, gauzes, foils or platinized $\mathrm{Pt}$ in various acid solutions to probe the kinetics, reaction order and mechanism. ${ }^{1-22}$ More recently, bulk polycrystalline-Pt (poly-Pt) disks with well-defined geometric areas 

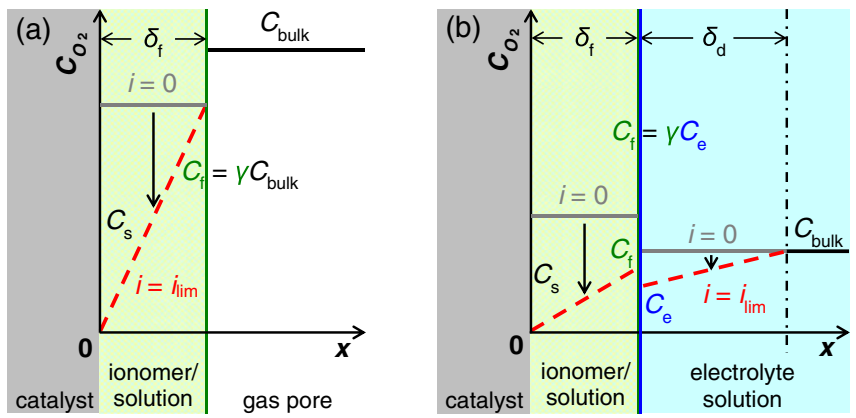

Figure 1. Schematic of a catalyst-electrolyte interface depicting the wellknown linear $\mathrm{O}_{2}$ diffusion model that can be represented by the K-L equation. The dotted line (red) represents $\mathrm{O}_{2}$ concentration gradients in both bulk electrolyte and film. (a) illustrates $\mathrm{O}_{2}$ diffusion in gas pores and thin electrolyte film e.g. floating electrode, gas phase wall-jet technique, and PEMFC. (b) illustrates $\mathrm{O}_{2}$ diffusion in electrolyte solution for controlled diffusion lengths e.g. poly-Pt RDE with a Nafion film. $\delta_{\mathrm{d}}$ is the boundary layer thickness in bulk electrolyte, and $\delta_{\mathrm{f}}$ is a thin electrolyte film thickness. $C_{\text {bulk }}, C_{\mathrm{e}}, C_{\mathrm{f}}$ and $C_{\mathrm{s}}$ are the $\mathrm{O}_{2}$ concentrations in the bulk, in the electrolyte solution at the solution | film interface, in the electrolyte film at the solution | film interface, and at the catalyst surface, respectively. $\gamma$ is partition coefficient between bulk and film phases, $i_{\lim }$ is the $\mathrm{O}_{2}$ diffusion limiting current.

have been widely employed in conjunction with RDE apparatus. Their remarkably high intrinsic activity combined with an electrochemical area $(\mathrm{RF} \sim 1.5)$ comparable to their geometric surface area qualifies them as a valuable sensor of trace impurity levels (in the cell glassware and electrolyte) that adsorb on and poison active ORR sites. The SA of bulk poly-Pt is thus expected to provide a critical ORR activity benchmark; however, literature values are rarely in agreement. The reasons for the scatter in SA values include, but are not limited to: i) impurity levels of the electrochemical system, ii) conditioning/break-in protocol, iii) direction of potential sweep, iv) sweep rate, v) potential range of sweep, vi) inclusion/omission of corrections (solution resistance, background current), and ECA estimation method. Furthermore, the potential, temperature, pressure, electrolyte type, acid grade, and concentration at which the SA is reported vary between groups making comparison non-trivial. We have collected/extracted and presented ORR SA values for poly-Pt reported in the literature , $^{4,23-38}$ along with key measurement parameters in Fig. 2. As is evident, researchers conduct RDE experiments using a fairly wide range of protocol parameters, operating conditions and corrections that can significantly influence the reported SA. This state of affairs hinders direct comparisons and verification of the magnitude of SA between laboratories; we think an attempt to mitigate these difficulties through systematic studies is worthwhile.

Poly-Pt cannot only be used as a tool to determine the impurity level of the electrochemical system but can be considered to be a model electrode having a robust and reproducible surface that can be used to study the effect of protocols, operating conditions and electrolyte. A large number of experiments can be conducted on a single reusable poly-Pt to evaluate protocols and subsequently applied and reevaluated on more complex Pt/C systems. In part I of this manuscript, our primary motivation is to quantify the impact of trace impurities in the electrochemical cell glassware and perchloric acid electrolyte by using the magnitude of the measured $\mathrm{SA}$ of polycrystalline $\mathrm{Pt}$ disks as a metric. Secondly, we provide details on the impact of various correction factors that are applied to the raw data to obtain the final derived parameters that allows the facile comparison of ORR activity results between laboratories. Lastly, based on the results of evaluation of a broad range of protocols related to the electrochemical measurement of the ECA and ORR currents on both poly-Pt and $\mathrm{Pt} / \mathrm{HSC}$, we justify our selection based on the criteria of reproducibility of data and duration of experiments.

\section{Experimental}

Catalysts, chemicals, and reactant gases.-46.4 wt\% $\mathrm{Pt}$ on high surface area carbon electrocatalysts (TEC10E50E, TKK; $132.6 \mathrm{~m}^{2} / \mathrm{g}$ $\mathrm{CO}$ chemisorption, $2.6 \mathrm{~nm} \mathrm{XRD}$ ) henceforth referred to as Pt/HSC as well as bulk poly-Pt $\left(\phi=5 \mathrm{~mm}, 0.196 \mathrm{~cm}^{2}\right.$, embedded in a PTFE cylinder, Pine Instruments) were employed in RDE measurements. Deionized (DI) water $(>18.2 \mathrm{M} \Omega \cdot \mathrm{cm}$, TOC $<5 \mathrm{ppb}$ ) from a Milli Q system (Millipore) was used for acid dilutions and glassware cleaning. The following chemicals were used in electrolyte preparation and ink formulation: Isopropanol (IPA, CHROMASOLV Plus, for HPLC, 99.9\%, Sigma-Aldrich), Nafion solution (DE520, EW1000, $5 \mathrm{wt} \%, 0.924 \mathrm{~g} / \mathrm{mL}$, Sigma-Aldrich), $0.05 \mu \mathrm{m}$ alumina dispersion (Buehler Inc.), concentrated (conc.) sulfuric acid (Certified ACS Plus, Fisher Scientific), Nochromix (Godax Laboratories, Inc.), and 70\% perchloric acids sourced from: Veritas Doubly Distilled (GFS chemicals), Omni Trace Ultra (EMD Millipore), J.T. Baker ULTREX II

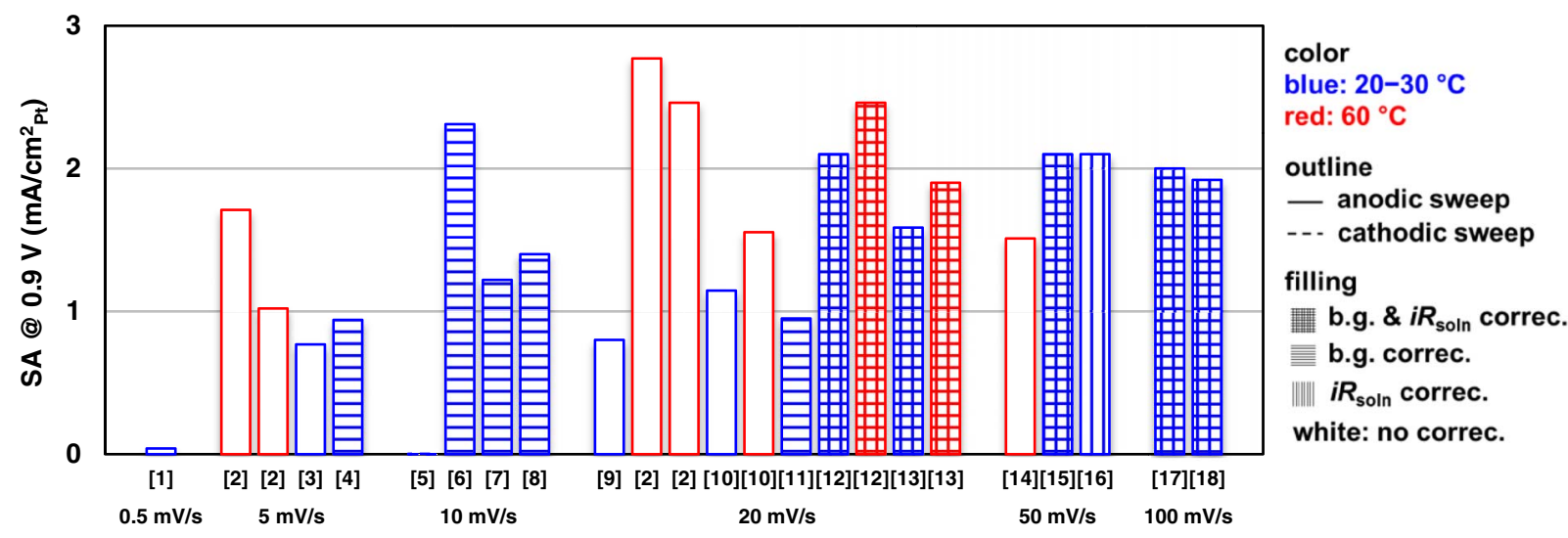

Figure 2. SA of bulk poly-Pt electrodes measured in $0.1 \mathrm{M} \mathrm{HClO}_{4}$ at $0.9 \mathrm{~V}$ extracted from literature. The scan rate, scan direction, measurement temperature, and corrections applied (horizontal line filling: b.g. corrected, vertical line filling: $i R_{\text {soln }}$ corrected, cross line filling: b.g. and $i R_{\text {soln }}$ corrected) are appropriately labeled. Ref. (1) Wakabayashi et al. ${ }^{7}$ (CFDE, SA at $0.76 \mathrm{~V}$ in Fig. 6 is extrapolated to $0.9 \mathrm{~V}$ using the obtained Tafel slope, $74 \mathrm{mV} /$ decade), (2) Gasteiger et al., ${ }^{4}$ (3) Ye et al. ${ }^{23}$ (SA at $0.9 \mathrm{~V}$ is calculated from raw current at $0.9 \mathrm{~V}$ and limiting current Fig. 2.), (4) Ohma et al. ${ }^{24}$ (5) Toda et al. ${ }^{25}$ (hardly visible on the figure due to close to zero value, SA at $0.76 \mathrm{~V}$ in Fig. 6 is extrapolated to $0.9 \mathrm{~V}$ assuming $74 \mathrm{mV} /$ decade), (6) Ke et al. ${ }^{26}$ (SA at $0.9 \mathrm{~V}$ is extracted from Fig. 10), (7) Sheng et al. $^{27}$ (SA at $0.9 \mathrm{~V}$ is extracted from Fig. 6 (b)), (8) Toyoda et al., ${ }^{28}$ (9) Stamenkovic et al. ${ }^{29}$ (SA at 0.9 V is extracted from Fig. 4.), (10) Mayrhofer et al. ${ }^{30}$ (SA at $0.9 \mathrm{~V}$ is extracted from Fig. 5), (11) Yang et al., ${ }^{31}$ (12) van der Vliet et al. ${ }^{32}$ (SA at $0.9 \mathrm{~V}$ is extracted from Fig. 4), (13) Stephens et al. ${ }^{33}$ (SA at $0.9 \mathrm{~V}$ is extracted from Fig. 6), (14) Stamenkovic et al. ${ }^{34}$ (SA at $0.9 \mathrm{~V}$ is extracted from Fig. 1), (15) Nesselberger et al., ${ }^{35}$ (16) Perez-Alonso et al. ${ }^{36}$ (SA at $0.9 \mathrm{~V}$ is extracted from Fig. 3), (17) Katsounaros et al., ${ }^{37}$ (18) Nesselberger et al. ${ }^{38}$ (SA at $0.9 \mathrm{~V}$ is extracted from Fig. S1 and S2). 


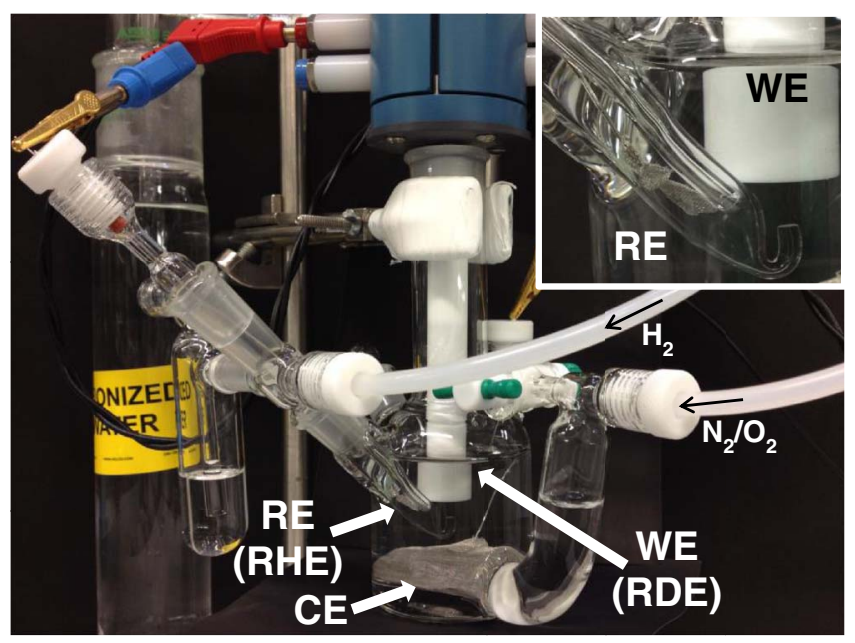

Figure 3. Photograph depicting in-house electrochemical cell system.

Ultrapure (AVANTOR), TraceSELECT (Sigma-Aldrich), Suprapur (Merck), Superior Reagent (ACS) (GFS chemicals), trace metal basis (Sigma-Aldrich), and ACS Reagent (Sigma-Aldrich). Measured amounts of $70 \% \mathrm{HClO}_{4}$ were poured directly from the original acid container into clean PFA or FEP bottles and diluted with DI water to prepare $\mathrm{HClO}_{4}$ electrolyte. No pipette or glassware was introduced in acid preparation steps to minimize contamination. All electrochemical measurements were carried out in $0.1 \mathrm{M} \mathrm{HClO}_{4}$ prepared from Superior Reagent (ACS) for Pt/HSC and Veritas Doubly Distilled for poly-Pt unless otherwise stated. Gases used in this study were all classified as ultrapure grade $\left(\mathrm{N}_{2}, 99.9999 \%, \mathrm{H}_{2}, 99.999 \%, \mathrm{O}_{2}, 99.9999 \%\right.$, CO $99.998 \%$ Matheson Gas).

Instrumentation.-A microbalance (UMX2, Mettler Toredo) and an ultrasonicator (FS30H, Fisher Scientific, output: $42 \mathrm{kHz}, 100 \mathrm{~W}$ ) were used for catalyst ink preparation. Autolab PGSTAT302N potentiostat operated with NOVA software from Metrohm was used to obtain cyclic voltammograms (CVs), ORR $I$ - $V$ polarization curves, insitu $i R$ correction and electrochemical impedance spectroscopy (EIS). RDE Rotators, PTFE rotator shafts glassy carbon (GC) and poly-Pt electrode tips were obtained from Pine Instruments. An optical microscope (AM4815ZT Dino-Lite Edge, Dino-Lite Digital Microscope) was routinely used to facilitate inspection of catalyst layers on GC. A JEOL JSM-7000F Field Emission Microscope was employed to obtain SEM images.

Electrode polishing and cleaning.-The GC and poly-Pt RDE tips were polished using $0.05 \mu \mathrm{m}$ alumina slurry, rinsed with DI water, sonicated in DI water for $\sim 30$ seconds followed by a final DI water rinse. The GC tips were dried using a nitrogen gun whereas poly-Pt RDE tips were sonicated in $0.1 \mathrm{M} \mathrm{HClO}_{4}$ electrolyte for $\sim 30$ seconds followed by rinsing in DI water prior to insertion in the electrochemical cell. During the brief transition period when the poly-Pt tips were being transferred to the cell, an extra precaution was taken by covering the Pt surface with a droplet of DI water or $0.1 \mathrm{M}$ $\mathrm{HClO}_{4}$ to curtail contamination from ambient atmosphere.

Electrochemical cell apparatus.-An in-house electrochemical cell (Fig. 3) having a volume of $130 \mathrm{~mL}$ was employed in all RDE measurements. A platinized Pt gauze having a surface area $>100 \mathrm{~cm}^{2}$ was employed as counter electrode (CE); a reversible hydrogen reference electrode (RHE) was ionically connected to the electrolyte in the main cell compartment via a Luggin capillary tip positioned close to the working electrode (WE). By employing a well-designed RHE rather than saturated calomel electrode (SCE) or $\mathrm{Hg} / \mathrm{Hg}_{2} \mathrm{SO}_{4}$ electrode, we avoid trace contamination caused by leakage of anions (e.g. $\mathrm{Cl}^{-}, \mathrm{SO}_{4}{ }^{2-}$ ) into the electrolyte as well as liquid junction potentials involved in the use of a salt bridge. Bulk poly-Pt disk electrode or a $\mathrm{Pt} / \mathrm{HSC}$ catalyst layer deposited on a GC tip functioned as the working electrode. The cell glassware and components were soaked in conc. acid/oxidizing agent in large containers placed in a hood. Subsequently, the glassware and components were rinsed thoroughly and boiled in DI water. Between electrochemical experiments, the glassware and components were stored submerged under DI water. Precise details of cell cleaning are discussed in the body of the manuscript. The electrochemical cell was rinsed with a diluted $\mathrm{HClO}_{4}$ solution three times before being filled with the solution that was used in experiments.

Electrochemical measurements.- Since various measurement protocols are evaluated and reported in this paper, specific details of the down-selected protocols are delineated in the Results section. An overview of general measurement details common to the protocols are provided here. The electrochemical cell was typically purged with the ultrapure $\mathrm{N}_{2}$ for $\sim 10$ min followed by blanketing of the cell with $\mathrm{N}_{2}$ during $\mathrm{CV}$ and conditioning measurements. The electrodes were first conditioned by cycling under $\mathrm{N}_{2}$ for a pre-determined number of cycles prior to measurements of solution $i R$ correction, CVs and ORR $I-V$ s. CVs were performed at a fixed scan rate and scan direction between two defined potentials for three cycles. The hydrogen underpotential deposition $\left(\mathrm{H}_{\mathrm{UPD}}\right)$ charge at the third cycle was integrated to obtain the electrochemical surface area (ECA) of the Pt, assuming a specific charge of $210 \mu \mathrm{C} / \mathrm{cm}^{2}{ }_{\mathrm{Pt}} \cdot{ }^{39-42} \mathrm{CO}$ stripping voltammetry was also conducted to complement and verify the ECA obtained from $\mathrm{H}_{U P D}$ measurements. The WE was held at a low potential during $\mathrm{CO}$ purge through the electrolyte followed by a $\mathrm{N}_{2}$ purge and flow. The ECA was estimated from CO stripping charge assuming a specific charge of 420 $\mu \mathrm{C} / \mathrm{cm}^{2}{ }_{\mathrm{Pt}} \cdot{ }^{43,44}$ Electrolyte solution resistance $\left(R_{\text {soln }}\right)$ between the RE and $\mathrm{WE}\left(\sim 21-23 \mathrm{ohm}\right.$ in $\left.0.1 \mathrm{M} \mathrm{HClO}_{4}\right)$ was measured via a built-in current interrupter or alternatively from the high frequency resistance (HFR) obtained from electrochemical impedance spectroscopy (EIS). Linear sweep voltammetry (LSV) was imposed after purging the cell with oxygen for $10 \mathrm{~min}$ to obtain the ORR activity with the $i R_{\text {soln }}$ drop corrected by the potentiostat during the LSV measurement. The background current was measured under $\mathrm{N}_{2}$ atmosphere at the identical rotation speed and scan rate as conducted under $\mathrm{O}_{2}$. The effect of temperature has been studied in the literature, and can be represented by the Arrhenius equation; ${ }^{15,29,30,45-47}$ the reported activation energy falls in the range $20-60 \mathrm{~kJ} / \mathrm{mol} .{ }^{15,29,30,45,46}$ In this work, all measurements have been conducted at ambient temperature $\left(23 \pm 2^{\circ} \mathrm{C}\right)$ to minimize impurities introduced due to decomposition of perchloric acid at temperature, to shorten experimental times as well as simplify safety aspects that become a concern for longer duration unattended durability studies.

Catalyst layer fabrication.-Catalyst inks were prepared by mixing $7.6 \mathrm{mg} \mathrm{Pt} / \mathrm{HSC}$ catalyst powder with $7.6 \mathrm{~mL}$ DI water, $2.4 \mathrm{~mL}$ IPA, and $40 \mu \mathrm{L}$ of $5 \mathrm{wt} \%$ Nafion solution. ${ }^{48,49}$ The catalyst inks were sonicated in an ice bath placed in the ultrasonicator for 20 minutes unless otherwise stated. A $10 \mu \mathrm{L}$ aliquot of the catalyst ink was pipetted onto the cleaned and polished GC tip mounted on an inverted rotator shaft at 0 or $100 \mathrm{rpm}$ (the choice of two initial rotation rates did not affect the appearance of the final catalyst film or magnitude of measured activity). The ink was subsequently dried under ambient conditions by increasing and maintaining the rotator speed at $700 \mathrm{rpm}$ for a period of $15 \mathrm{~min} .{ }^{50}$ We refer to this method of drying method of the deposited ink to form a film as 'rotational air drying' or RAD. For consistency of film quality and measured activity, results reported in Part I of the manuscript correspond to electrodes exclusively prepared using the RAD method.

\section{Results and Discussion}

Glassware and electrolyte impurities.-The use of bulk poly-Pt has been prevalent in the literature either as a wire or disk for the last 50 years and has often been used to investigate ORR kinetics. 

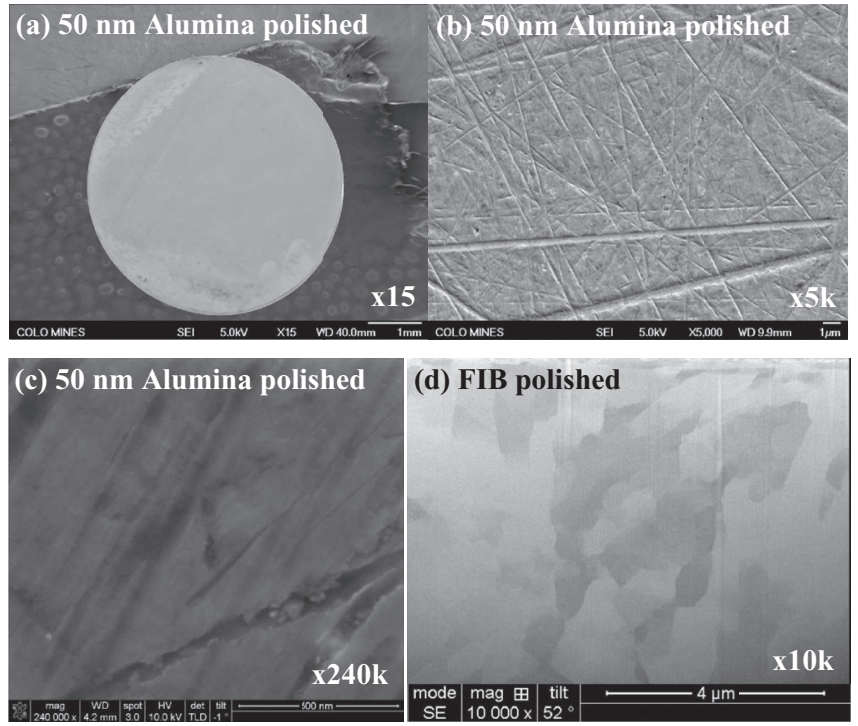

Figure 4. SEM images of poly-Pt electrode at magnifications of (a) $\mathrm{x} 15$, (b) $\times 5 \mathrm{k}$, (c) $\times 240 \mathrm{k}$ showing surface roughness and deep grooves. (d) Crosssectional image of poly-Pt prepared by focused ion beam etching revealing grain boundaries.

Poly-Pt has been reported to possess a much higher intrinsic or specific activity compared to nanoparticle $\mathrm{Pt} / \mathrm{C}$; however its low geometric surface area ( $\mathrm{RF} \sim 1.1-1.3$ based on $210 \mu \mathrm{C} / \mathrm{cm}^{2}{ }_{\mathrm{Pt}}$ ) renders it highly sensitive to trace impurities that may adsorb on its surface during electrochemical studies. Moreover, being a bulk material having appreciable thickness (few $\mathrm{mm}$ ), it is extremely durable and can be used repeatedly with cleaning and polishing. Although poly-Pt disk surfaces can be polished easily to a mirror finish, SEM images (Fig. 4) reveal an exceedingly rough surface featuring deep grooves, scratches, and even dents for both as-purchased/unused as well as polished/used electrodes. Based on SEM images, one can speculate that the $\mathrm{H}_{\text {UPD }}$ charge, and therefore, roughness factor (RF) is greatly influenced by the physical roughness in addition to grain size/crystal orientation that are observable only after sufficient amount of material has been removed to obtain an exceedingly smooth surface by focused ion beam (FIB, Ga ion) etching. The magnitude of the integrated charge under the $\mathrm{H}_{\text {UPD }}$ peaks $\left(195-210 \mu \mathrm{C} / \mathrm{cm}^{2}{ }_{\mathrm{Pt}}\right)^{30,39-42,45}$ for poly-Pt is still under debate. For simplicity, we have selected the conventional value of 210 $\mu \mathrm{C} / \mathrm{cm}^{2}{ }_{\mathrm{Pt}}$; the SA for poly-Pt would be lower by $\sim 7 \%$ corresponding to an $\mathrm{H}_{\mathrm{UPD}}$ charge of $195 \mu \mathrm{C} / \mathrm{cm}^{2} \mathrm{Pt}$.

It is well-known that the specific activity of Pt based electrocatalysts in sulfuric and phosphoric acid electrolytes are significantly lower than that in perchloric acid due to (bi)sulfate and phosphate anion adsorption. ${ }^{10,29,35,47,51-54}$ Perchloric acid is considered to be a non-adsorbing or weakly adsorbing electrolyte ${ }^{55-57}$ and has been used to simulate the role of Nafion ionomer in PEMFCs. Active ORR sites on Pt are extremely susceptible to poisoning by ppm quantities of impurity anions such as sulfate, chloride and nitrate..$^{54,57-65}$ Trace chloride and sulfate impurities (ppm-ppb level) when introduced into $0.1 \mathrm{M} \mathrm{HClO}_{4}$ have been shown to change $\mathrm{CV}$ profiles and negatively affect the ORR activity on platinum surfaces..$^{54,57,65,66}$ Even 4 ppm of chloride ions are known to result in an order of magnitude loss in the ORR activity. ${ }^{54}$ Variable and uncontrolled impurity levels would cause a significant scatter in ORR activity measurements; therefore, it is indispensable to use clean electrochemical cell glassware, rotator shafts, electrode tips and electrolytes implemented with a robust carefully controlled cleaning procedure.

Our standard cleaning procedure involves an overnight soak of the cell glassware and components in conc. sulfuric acid followed by an overnight soak in Nochromix solution. The frequency of these soaks has to be tailored to the type and amount of contaminants introduced
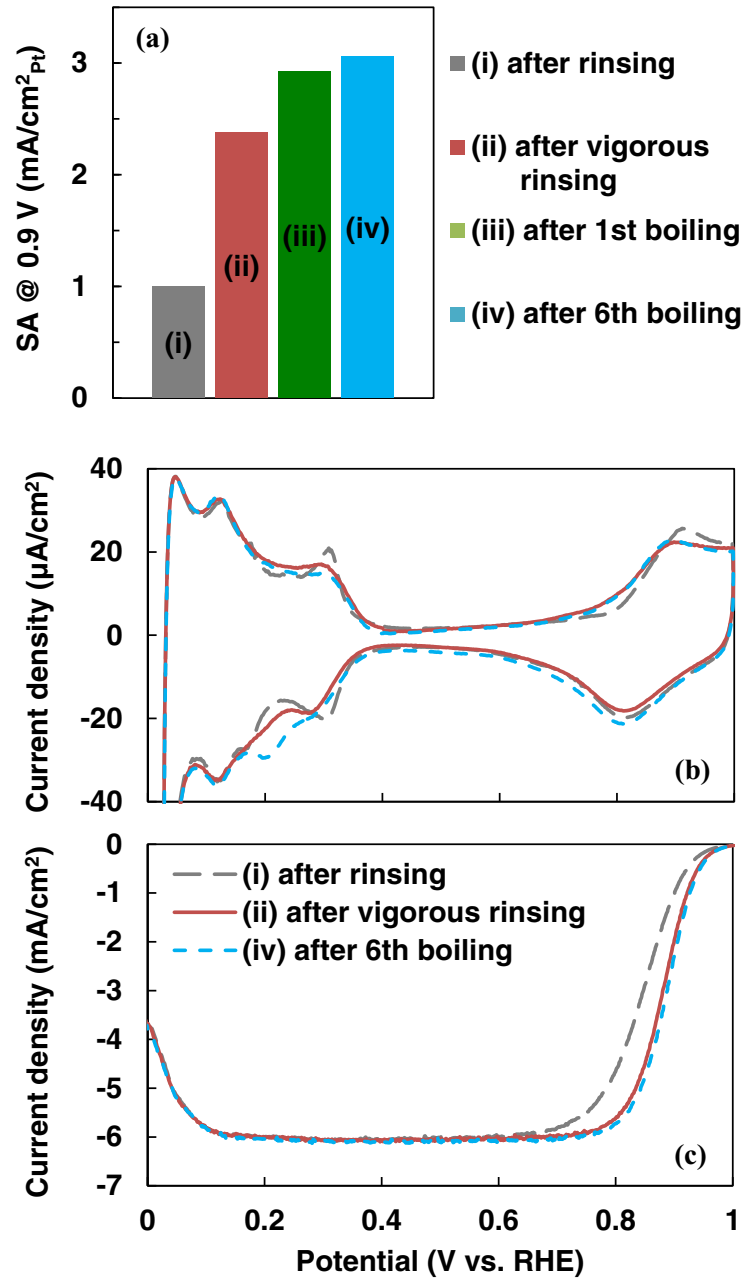

Figure 5. The impact of removal of impurities at several intermediate stages of cleaning: (a) SA at $0.9 \mathrm{~V}$ obtained from (c), (b) $\mathrm{CV}_{\text {s under }} \mathrm{N}_{2}$, (c) ORR $I-V$ curves after b.g. correction. All ORR $I-V$ measurements for poly-Pt conducted in $0.1 \mathrm{M} \mathrm{HClO}_{4}$ under the conditions: $20 \mathrm{mV} / \mathrm{s}, 1600 \mathrm{rpm},-0.01$ to $1.0 \mathrm{~V}$, anodic sweep, $i R_{\text {soln }}$ corrected.

into the cell from the working electrode materials during experiments. A review of the literature shows a wide range of cleaning procedures formulated by researchers including: soaks in Aqua Regia, ${ }^{67}$ hot conc. nitric ${ }^{26}$ or sulfuric acid, ${ }^{19}$ acidified potassium permanganate, ${ }^{5,68}$ mixtures of conc. sulfuric acid $/ 30 \%$ hydrogen peroxide, ${ }^{36}$ conc. sulfuric acid/Nochromix ${ }^{69}$ or conc. nitric acid/conc. sulfuric acid. ${ }^{47,70-72}$ Following the acid soaks, the electrochemical cell is immersed in DI water and brought to a boil; this process is repeated from 3-6 times with the DI water being replaced after each boil. Immediately prior to commencement of RDE experiments, the electrochemical cell is rinsed 2-3 times in $0.1 \mathrm{M} \mathrm{HClO}_{4}$. The PTFE rotator shaft is rinsed with DI water before and after experiments. The electrochemical cell is submerged under DI water in a covered beaker between experiments to avoid the introduction contaminants from air. An alternative to boiling the cell in DI water is to place the inverted glassware in the path of DI water vapor that flow over it, condenses and drips down. ${ }^{68,72}$ Sheeting of water on the glassware surface rather than beading is a qualitative reflection of the general absence of organic impurities.

Figure 5a depicts the change in SA of poly-Pt extracted from the ORR $I$ - $V$ curves in Fig. $5 \mathrm{c}$ to the progressive elimination of impurities in the cell glassware. Vigorous rinsing prior to boiling in DI water resulted in poly-Pt attaining a SA $>2.5 \mathrm{~mA} / \mathrm{cm}^{2}{ }_{\mathrm{Pt}}$, in this instance, in fewer than 3 rinses. The $\mathrm{CV}$ response exhibits a slight positive shift in the onset of oxides as well as more pronounced peaks in the $\mathrm{H}_{\text {UPD }}$ 


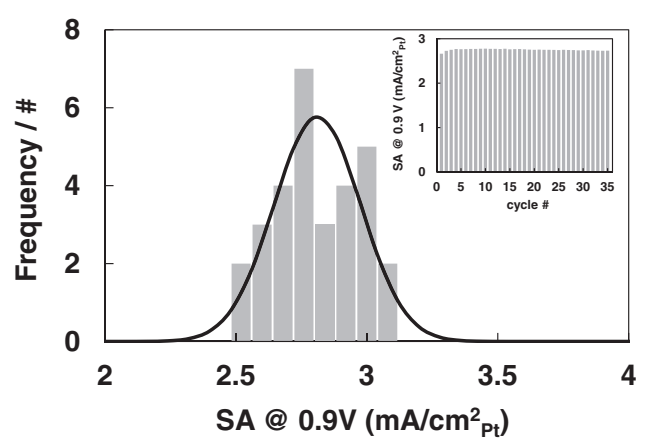

Figure 6. Gaussian distributions (30 independent experiments) for the SA of poly-Pt at $0.9 \mathrm{~V}$. The inset depicts stability of SA for consecutive $I-V$ curve measurements. All ORR $I-V$ measurements conducted in $0.1 \mathrm{M} \mathrm{HClO}_{4}$ under the conditions: $20 \mathrm{mV} / \mathrm{s}, 1600 \mathrm{rpm},-0.01$ to $1.0 \mathrm{~V}$, anodic sweep.

regime near $0.3 \mathrm{~V}$ that are related to anion adsorption. Additional rinses are recommended if cell glassware contain parts that are less easy to rinse such as glass frit and Vycor. We note that our DI water typically exhibited a TOC of $<5 \mathrm{ppb}$; for $0.1 \mathrm{M} \mathrm{HClO}_{4}$ prepared using DI water the TOC value is $\sim 20 \mathrm{ppb}$ and did not affect the SA of poly-Pt. It should also be noted that once the cell glassware is properly cleaned and rinsed with DI water, the entire process is not always necessary to maintain cleanliness of the cell glassware; boiling in DI water 2-3 times after an experiment enables the cell glassware to recover from trace amounts of impurities introduced in experiments. However, more frequent cleaning with strong acids/oxidizing agents is necessary if significant contamination of the cell is expected from leached non-noble metals, alternate supports, etc. Figure 6 illustrates the measured SA of a poly-Pt electrode over 30 independent trials; the magnitude of the SA is $2.8 \pm 0.2(6 \%) \mathrm{mA} / \mathrm{cm}^{2}{ }_{\mathrm{Pt}}$ at $0.9 \mathrm{~V}$ vs. RHE in $0.1 \mathrm{M} \mathrm{HClO}_{4}$ at $25^{\circ} \mathrm{C}$ and $100 \mathrm{kPa} \mathrm{O}_{2}$. The ORR $I-V$ sweeps were repeated for 35 consecutive cycles without refreshing/replacing the electrolyte and demonstrated excellent stability (Fig. 6 inset) over the $1 \mathrm{~h}$ duration of the experiment. Since the SA of state-of-the-art fuel cell catalysts in RDE studies have been demonstrated to exceed $2.0 \mathrm{~mA} / \mathrm{cm}^{2}{ }_{\mathrm{Pt}},{ }^{49,73}$ poly-Pt SA $>2.0 \mathrm{~mA} / \mathrm{cm}^{2}{ }_{\mathrm{Pt}}$ that remains invariant over an hour is a reasonable and necessary condition to validate the electrochemical system and obtain reliable measurements.

The choice of perchloric acid grade (a measure of impurity levels and type of impurity) can be as critical as the cleanliness of the electrochemical cell. Commercially available $70 \% \mathrm{HClO}_{4}$ is known to consist of trace impurities (0.1-10 ppm) of chloride, sulfate, phosphate and nitrate ions; standardized ACS methods to determine trace amount of anion species are typically employed by manufacturers. The deleterious effect of the adsorption of various anions on active ORR sites of $\mathrm{Pt}$ is well established in the literature. ${ }^{51,54,58-65}$ Since the measured SA of poly-Pt will be impacted by the impurities in the electrolyte, we evaluated perchloric acid from 8 sources/suppliers as listed in Experimental section; the criterion for down-selections was based on the magnitude of the measured poly-Pt SA. Table I is populated with impurity type and ppm levels for several of the sources of

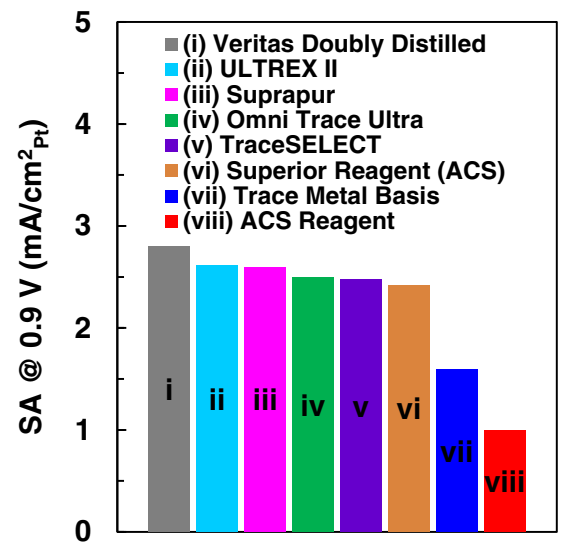

Figure 7. Effect of impurity levels $\left(\mathrm{HClO}_{4}\right.$ grade) on the $\mathrm{SA}$ of poly-Pt at 0.9 $\mathrm{V}$ in $0.1 \mathrm{M} \mathrm{HClO}_{4}$ measured under the conditions: $20 \mathrm{mV} / \mathrm{s}, 1600 \mathrm{rpm},-0.01$ to $1.0 \mathrm{~V}$, anodic sweep.

perchloric acid that are available. With the exception of Trace Metal Basis and ACS Reagent that clearly resulted in significantly lower $\mathrm{SA}\left(\sim 1.0 \mathrm{~mA} / \mathrm{cm}^{2}{ }_{\mathrm{Pt}}\right)$ and Veritas Doubly Distilled that resulted in the highest SA, the other five grades resulted in SAs that were comparable as shown in Fig. 7. We observe a $10 \%$ loss in SA for poly-Pt and $2-4 \%$ loss for Pt/HSC if Superior Reagent (ACS) is employed instead of Veritas Doubly Distilled.

The choice of $\mathrm{HClO}_{4}$ concentration is a compromise between using a higher concentration containing higher impurity levels and a lower concentration that leads to significant solution resistance and errors associated with its correction. It should be noted that using the same electrolyte for long periods of time especially at temperature also leads to decomposition of the acid and generation of small quantities of chloride ions. ${ }^{47}$ Figure $8 \mathrm{a}$ shows the CVs and Fig. 8b depicts the corresponding ORR $I-V$ curves to illustrate the impact of perchloric acid concentration on the SA of poly-Pt; the inset of Fig. $8 \mathrm{~b}$ shows a plot of $R_{\text {soln }}$ vs. acid concentration. As we increase the perchloric acid concentration from $0.004 \mathrm{M}$ to $0.50 \mathrm{M}$, the SA plummets due to the higher level of impurities. The CVs show a positive shift in the onset of oxide formation (at $\sim 0.7-0.8 \mathrm{~V}$ ) together with an increase of the peak height in the $\mathrm{H}_{\mathrm{UPD}}$ regime, both of which are indicators of anion adsorption on Pt. In the Tafel plot (Fig. 8b), at low molarities (low ionic conductivities, esp. $0.004 \mathrm{M}$ ) significant errors are introduced when correcting for solution resistance (higher slope at higher current density) rendering the data inadmissible.

Corrections. - In order to obtain ORR kinetic currents for a $\mathrm{Pt}$ catalyst, it is necessary to correct the raw ORR $I-V$ data acquired from RDE measurements for solution resistance, $R_{\text {soln }}$, capacitive or background (b.g.) currents, as well as compensate for $\mathrm{O}_{2}$ diffusion in bulk electrolyte applying the K-L equation. In the following sections, we address the quantification of these correction factors and their impact on the ORR activity reported in this work and the literature.

Table I. Impurity anion concentrations (ppm) obtained from $\mathrm{HClO}_{4}$ suppliers specifications.

\begin{tabular}{cccccc} 
Compound/ppm & $\begin{array}{c}\text { Veritas Doubly } \\
\text { Distilled (GFS chemical) }\end{array}$ & $\begin{array}{c}\text { Superior Reagent } \\
\text { (ACS) (GFS chemical) }\end{array}$ & $\begin{array}{c}\text { TraceSELECT Ultra } \\
\text { (Sigma-Aldrich) }\end{array}$ & $\begin{array}{c}\text { TraceSELECT } \\
\text { (Sigma-Aldrich) }\end{array}$ & $\begin{array}{c}\text { ACS Reagent } \\
\text { (Sigma-Aldrich) }\end{array}$ \\
\hline $\mathrm{Cl}^{-}$ & 0.1 & 3 & $\leq 10$ & $\leq 10$ & $\leq 10$ \\
$\mathrm{SO}_{4}{ }^{2-}$ & 1 & 10 & $\leq 0.2$ & $\leq 1$ \\
$\mathrm{PO}_{4}{ }^{3-}$ & 0.1 & 5 & $\leq 0.2$ & $\leq 10$ \\
total N & 1 & 10 & NA & NA
\end{tabular}

Concentration of each anion decreases to $1 / 24\left(0.004-0.4 \mathrm{ppm}\right.$ for $\left.\mathrm{Cl}^{-}\right)$when diluted to $0.5 \mathrm{M}$ and to $1 / 70\left(0.001-0.1 \mathrm{ppm}\right.$ for $\left.\mathrm{Cl}^{-}\right)$when diluted to $0.1 \mathrm{M}$. Anion impurity data not available for Omni Trace Ultra, J.T. Baker ULTREX II Ultrapure and Trace Metal Basis. a: Nitrogen based impurities such as nitrates. 

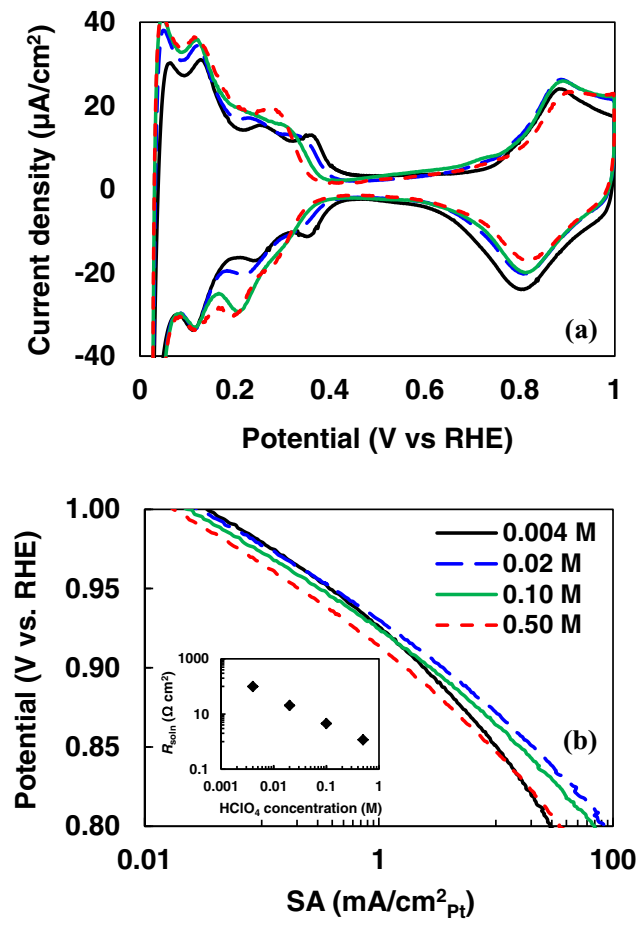

Figure 8. Effect of $\mathrm{HClO}_{4}$ concentration on (a) $\mathrm{CVs}$ under $\mathrm{N}_{2}$ and (b) ORR Tafel plots for poly-Pt. All ORR $I-V$ measurements conducted at $20 \mathrm{mV} / \mathrm{s}$, -0.01 to $1.0 \mathrm{~V}$, anodic sweep. Inset (b) shows $\log -\log$ plot of $R_{\text {soln }} \mathrm{vs}$. $\mathrm{HClO}_{4}$ concentrations.

Corrections.-Solution resistance $\left(R_{\text {soln }}\right)$. - A finite length/volume of electrolyte $(10-20 \mathrm{~mm})$ is present between the RE and WE in conjunction with a narrow ionic path through the RE Luggin capillary tip. Thus, even in the absence of a salt bridge and liquid junction, the electrolyte or solution resistance $\left(R_{\text {soln }}\right)$ between the RE and WE is non-negligible and has to be compensated. ${ }^{74}$ Potentiostats such as the Autolab allow for the measurement of $R_{\text {soln }}$ immediately prior to the experiment using the 'current interrupt' technique; the potentiostat is fed the value of $R_{\text {soln }}$ and applies an in-situ corrected potential that takes into account $i R_{\text {soln }}$ loss during data acquisition. An oscillatory behavior observed during $I-V$ data acquisition implies overcorrection of $i R_{\text {soln }}$; hence, typically $\sim 95 \%$ of the measured $R_{\text {soln }}$ is applied. It is also possible to verify $R_{\text {soln }}$, from the real intercept or high frequency resistance (HFR) of Nyquist plots $\left(Z^{\prime}\right.$ vs. $\left.Z^{\prime \prime}\right){ }^{75,76} R_{\text {soln }}$ is also dependent on the ionic conductivity of the electrolyte which is a function of the acid molarity; $R_{\text {soln }}$ extracted from Nyquist plots for four different molarities of perchloric acid are plotted in the inset of Fig. 8 b. $R_{\text {soln }}$ in $0.5,0.1,0.02$ and $0.004 \mathrm{M} \mathrm{HClO}_{4}$ were determined to be 502, 103, 23 and 6 ohms, respectively. It should be noted that in MEAs of PEMFCs, an $i R$ correction is conventionally applied after obtaining the $I-V$ polarization curve. Since some potentiostats used for RDE measurements do not have the capability of executing in-situ $i R$ corrections, we also experimented with post-measurement corrections and found identical results.

Corrections.-Background (b.g.).-The signature CV profile observed for Pt consists of: i) a double layer charging current frequently but debatably assumed to be constant in the entire voltage range $(\sim 0$ $1.0 \mathrm{~V}$ ), ii) hydrogen adsorption and desorption pseudo-capacitive currents in the range $\sim 0-0.4 \mathrm{~V}$, and, iii) platinum surface oxidation and reduction currents in the range $\sim 0.7-1.0 \mathrm{~V}$. For the case of nanoparticle Pt supported on carbon blacks (Pt/C), a significant additional pseudo-capacitive current contribution arises from the high surface area carbon support. The magnitude of b.g. current is amplified with an increase in total catalyst loading $\left(\mu \mathrm{g}_{\mathrm{cat}} / \mathrm{cm}^{2}\right)$ and surface area $\left(\mathrm{m}^{2} / \mathrm{g}_{\mathrm{Pt}}\right)$, and a decrease in the $\mathrm{wt} \%$ of $\mathrm{Pt} / \mathrm{C}$. Furthermore, the b.g. current is directly proportional to the imposed scan rate. The

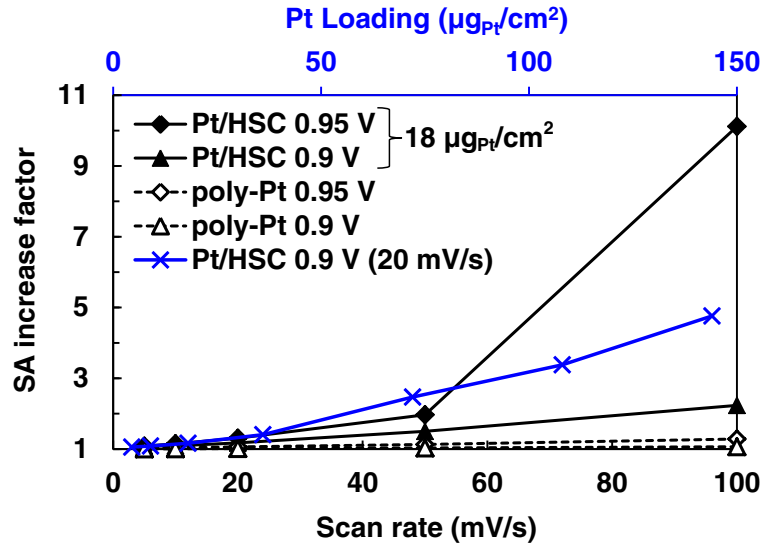

Figure 9. Effect of b.g. correction at $0.9 \mathrm{~V}$ and $0.95 \mathrm{~V}$ for poly-Pt and Pt/HSC on the SA increase factor as a function of scan rate. Effect of b.g. correction at $0.9 \mathrm{~V}$ for $\mathrm{Pt} / \mathrm{HSC}$ on the SA increase factor also shown as a function of Pt loading (second y-axis). All ORR $I-V$ measurements conducted in $0.1 \mathrm{M}$ $\mathrm{HClO}_{4}$ under the conditions: $1600 \mathrm{rpm},-0.01$ to $1.0 \mathrm{~V}$, anodic sweep, $i R_{\text {soln }}$ corrected.

magnitude of b.g. current can be obtained by measuring $I$ - $V$ curves under $\mathrm{O}_{2}$ and $\mathrm{N}_{2}$ using identical experimental parameters (scan rate, direction, rotation rate) and subsequently subtracting the $I-V$ curve under nitrogen from that under oxygen. ${ }^{35,52,77,78}$ This correction would allow us to obtain the ORR activity of Pt independent of the capacitive currents of Pt and carbon black, but also facilitates comparison of results for varying catalyst loadings, Pt wt\%, support type and area. After implementing b.g. correction, the resulting ORR kinetic current has a higher magnitude for anodic (positive) sweeps and lower value for cathodic (negative) sweeps.

It should be noted that the apparent gain in measured ORR activity post-b.g. correction is not actually available to generate useful work in practical PEMFCs causing some researchers to debate its application. Sugawara et al. ${ }^{79}$ used a 'shielding technique' to determine the actual b.g. current under $\mathrm{O}_{2}$ flow and found negligible differences between b.g. currents under $\mathrm{N}_{2}$ and $\mathrm{O}_{2}$; similar conclusions have also been drawn from quartz-crystal microbalance ${ }^{80}$ and PEMFC ${ }^{81}$ studies. Therefore in this paper, we present kinetic currents corrected for b.g. current and explicitly account for the contribution of the applied correction. Figure 9 illustrates the quantitative impact of the background current on SA ( $i R_{\text {soln }}$ applied prior to b.g. correction) as a function of scan rate and potential for poly-Pt and Pt/HSC. Figure 9 also shows the impact of the b.g. correction on SA at $0.9 \mathrm{~V}$ measured at $20 \mathrm{mV} / \mathrm{s}$ as a function of $\mathrm{Pt}$ loading for $46.4 \mathrm{wt} \% \mathrm{Pt} / \mathrm{HSC}$. The magnitude of $\mathrm{SA}$ of Pt/HSC after b.g. correction is augmented by a factor of 1.05 at $4.5 \mu \mathrm{g} / \mathrm{cm}^{2}{ }_{\mathrm{Pt}}$ and 4.8 at $144 \mu \mathrm{g} / \mathrm{cm}^{2}{ }_{\mathrm{Pt}}$. Table II summarizes the effect of various corrections including b.g. correction for catalysts evaluated in this work as well as that reported in literature. ${ }^{4,26,74,82,83}$ The b.g. correction trends observed in the literature qualitatively agree with the behavior discussed above.

In relation to the specifics of the methods used by the potentiostat to generate potential scan profiles, viz., staircase $(1 \mathrm{mV}$ step, current sampling at the end of each step) and linear (analog) sweeps, both resulted in nearly identical kinetic currents after background correction. Corrections.-Koutecký-Levich equation.-The kinetic current $i_{\mathrm{k}}$ is estimated from well-known K-L equation as expressed in Eq. 1. For an $\mathrm{O}_{2}$ concentration in the bulk electrolyte $\left(C_{\text {bulk }}\right)$, the actual concentration of $\mathrm{O}_{2}$ at the electrode surface $\left(C_{\mathrm{s}}\right)$ is lower than $C_{\text {bulk }}$ due to consumption of $\mathrm{O}_{2}$ as a function of current density (Fig. 1). The K-L equation is conventionally used to account for this difference in concentration so that $i_{\mathrm{k}}$ at $C_{\mathrm{bulk}}$ is obtainable. It is essential to note that the $\mathrm{K}-\mathrm{L}$ correction is applied after the raw current is corrected for $i R_{\text {soln }}$ and b.g. currents and is therefore dependent on these corrections. The relative error encountered in the application of the K-L equation to obtain $i_{\mathrm{k}}$ is dependent on $i / i_{\mathrm{d}}$ and rises as we approach the $\mathrm{O}_{2}$ diffusion 
Table II. Summary of the effect of corrections (background current and $i R_{\text {soln }}$ ) on SA at $0.9 \mathrm{~V}$ vs. RHE for Pt/C electrocatalysts evaluated in this work and comparison to the literature.

\begin{tabular}{|c|c|c|c|c|c|c|c|c|c|}
\hline \multirow[b]{2}{*}{ Catalyst } & \multirow{2}{*}{$\begin{array}{c}L_{\mathrm{Pt}} \\
\left(\mu \mathrm{g}_{\mathrm{Pt}} / \mathrm{cm}^{2}\right)\end{array}$} & \multirow{2}{*}{$\begin{array}{c}\mathrm{ECA} \\
\left(\mathrm{m}^{2} / \mathrm{g}_{\mathrm{Pt}}\right)\end{array}$} & \multirow{2}{*}{$\begin{array}{c}T \\
\left({ }^{\circ} \mathrm{C}\right)\end{array}$} & \multirow{2}{*}{$\begin{array}{l}\text { Scan rate } \\
(\mathrm{mV} / \mathrm{s})\end{array}$} & \multirow{2}{*}{$\begin{array}{c}\text { Potential range } \\
\text { (V vs. RHE) }\end{array}$} & \multicolumn{3}{|c|}{ SA increase factor with corrections } & \multirow[b]{2}{*}{ Ref. } \\
\hline & & & & & & b.g. & $i R_{\text {soln }}$ & b.g. \& $i R_{\text {soln }}$ & \\
\hline $46.4 \mathrm{wt} \% \mathrm{Pt} / \mathrm{HSC}$ (TKK) & 18 & $99 \pm 5$ & 23 & 5 & $-0.01 \rightarrow 1.0$ & 1.08 & $1.35(\sim 23 \Omega)$ & 1.46 & This work \\
\hline $46.4 \mathrm{wt} \% \mathrm{Pt} / \mathrm{HSC}$ (TKK) & 18 & $99 \pm 5$ & 23 & 10 & $-0.01 \rightarrow 1.0$ & 1.09 & $1.43(\sim 23 \Omega)$ & 1.55 & This work \\
\hline $46.4 \mathrm{wt} \% \mathrm{Pt} / \mathrm{HSC}$ (TKK) & 18 & $99 \pm 5$ & 23 & 20 & $-0.01 \rightarrow 1.0$ & 1.18 & $1.38(\sim 23 \Omega)$ & 1.62 & This work \\
\hline $46.4 \mathrm{wt} \% \mathrm{Pt} / \mathrm{HSC}$ (TKK) & 18 & $99 \pm 5$ & 23 & 50 & $-0.01 \rightarrow 1.0$ & 1.52 & $1.37(\sim 23 \Omega)$ & 2.09 & This work \\
\hline $45.9 \mathrm{wt} \% \mathrm{Pt} / \mathrm{HSC}$ (TKK) & 12.7 & 80 & 60 & 5 & $0 \rightarrow 1.0$ & 1.04 & - & - & 4 \\
\hline $45.9 \mathrm{wt} \% \mathrm{Pt} / \mathrm{HSC}$ (TKK) & 12.7 & 80 & 60 & 20 & $0 \rightarrow 1.0$ & 1.15 & - & - & 4 \\
\hline $46 \mathrm{wt} \% \mathrm{Pt} / \mathrm{HSC}$ (TKK) & 9.9 & 96 & r.t. & 10 & $0.1 \rightarrow 1.1$ & - & $1.57(\sim 35 \Omega)$ & - & 82 \\
\hline $46 \mathrm{wt} \% \mathrm{Pt} / \mathrm{HSC}$ (TKK) & 11.7 & 79 & 30 & 10 & $0.06(30 \mathrm{~s}) \rightarrow 1$ & 1.1 & - & - & 26 \\
\hline $5 \mathrm{~nm} \mathrm{Pt} / \mathrm{C}(\mathrm{TKK})$ & 18 & - & 20 & 20 & $0.02 \rightarrow 1.05$ & - & $1.46(28.5 \Omega)$ & - & 74 \\
\hline $5 \mathrm{~nm} \mathrm{Pt} / \mathrm{C}(\mathrm{TKK})$ & 18 & - & 60 & 20 & $0.02 \rightarrow 1.05$ & - & $1.33^{\mathrm{a}}(16.5 \Omega)$ & - & 74 \\
\hline $19.7 \mathrm{wt} \% \mathrm{Pt} / \mathrm{V}$ (E-TEK) & 20 & $61-63 \pm 2$ & 30 & 20 & $0.05 \rightarrow 1.03$ & 1.16 & $1.46^{\mathrm{b}}(\sim 20 \Omega)$ & 1.69 & 83 \\
\hline $40 \mathrm{wt} \% \mathrm{Pt} / \mathrm{V}(\mathrm{JM})$ & 20 & $49 \pm 1$ & 30 & 20 & $0.05 \rightarrow 1.03$ & 1.13 & $1.35^{\mathrm{b}}(\sim 20 \Omega)$ & 1.53 & 83 \\
\hline $46.6 \mathrm{wt} \% \mathrm{Pt} / \mathrm{V}$ (IP) & 20 & $80 \pm 1$ & 30 & 20 & $0.05 \rightarrow 1.03$ & 1.18 & $1.34^{\mathrm{b}}(\sim 20 \Omega)$ & 1.59 & 83 \\
\hline
\end{tabular}

$L_{\mathrm{Pt}}$ and $T$ are Pt loading and temperature, respectively. SA is obtained at $0.9 \mathrm{~V}$ vs. RHE in anodic sweep. All Pt/HSC (TKK) catalysts are TEC10E50E. SA increase factors for this work were calculated in relation to SA value at each scan rate. a: calculated from SAs in Table III ${ }^{74}$ b: calculated from SAs in Table III. ${ }^{83}$

limiting current $i_{\mathrm{d}} \cdot{ }^{30,84}$ Mayrhofer et al. ${ }^{30}$ have prescribed that the potential at which ORR activity is measured should satisfy the relation $0.1<i / i_{\mathrm{d}}<0.8$ to minimize inaccuracies. Vidal-Iglesias et al. ${ }^{84}$ carried out a detailed mathematical analysis that projected $\mathrm{x} 3$ magnification of error in $i_{\mathrm{k}}$ at $i / i_{\mathrm{d}}=0.5$ for an arbitrary experimental error in the measured raw current. It is thus advisable to report the measured ORR activity at potentials corresponding to the range $\left(0.1<i / i_{\mathrm{d}}<0.5\right)$.

Corrections.-Consolidation.-Figure 10 summarizes the absolute (a: poly-Pt, b: Pt/HSC) and normalized (c: poly-Pt, d: Pt/HSC) kinetic currents with the individual contributions of $i R_{\text {soln }}$ (orange), b.g. (green) and K-L (hatched) corrections as well as the specific raw currents (gray). At $0.9 \mathrm{~V}$ and $20 \mathrm{mV} / \mathrm{s}$, poly-Pt (a) exhibits kinetic currents of $\sim 3 \mathrm{~mA} / \mathrm{cm}^{2}{ }_{\mathrm{Pt}}$ while Pt/HSC (b) shows $\sim 0.5 \mathrm{~mA} / \mathrm{cm}^{2}{ }_{\mathrm{Pt}}$. From Figs. $10 \mathrm{a}, 10 \mathrm{~b}$, it appears that both poly-Pt and Pt/HSC show similar trends for kinetic currents with scan rates and potential; in contrast, b.g. current corrections are significantly higher for Pt/HSC due to contributions from Pt nano-particles and carbon black support. The individual contributions of the current components in Figs. 10a and 10b can be amplified by normalizing them to the total absolute currents to reveal $\%$ contributions as depicted in Figs. 10c and 10d. At $0.95 \mathrm{~V}$, we can now clearly observe that the contribution from b.g. is much higher than at $0.85 \mathrm{~V}$ and $0.9 \mathrm{~V}$ for both poly-Pt and Pt/HSC. At $0.85 \mathrm{~V}$, the total K-L corrections (green + orange + gray hatched bars) can be a significant component ( $\sim 85 \%$ at $50 \mathrm{mV} / \mathrm{s}, \mathrm{Pt} / \mathrm{HSC})$ of the total normalized currents. For $\mathrm{Pt} / \mathrm{HSC}$, at $20 \mathrm{mV} / \mathrm{s}$, the $\%$ contribution of all corrections (all except gray bar) applied to obtain kinetic current follows the trend $\sim 85 \%(0.85 \mathrm{~V})>\sim 70 \%(0.9 \mathrm{~V})>\sim 50 \%(0.95$ $\mathrm{V})$. For all potentials, at increasing scan rates, the $\%$ contributions of $i R_{\text {soln }}$, b.g. and K-L corrections increase progressively. The K-L corrections (hatched bars) are considered to be free of error based on the assumption of negligible experimental errors in the measurement of raw currents. Albeit, as discussed previously, a magnification of any experimental error in measured raw currents would have a greater impact at higher $i / i_{\mathrm{d}}$. The errors in measured raw currents (e.g. $0.95 \mathrm{~V}$ ) are expected to be greater at higher potentials (lower currents) especially when measurements are conducted using a fixed current range. $i R_{\text {soln }}$ corrections (orange) are accurate within $90-95 \%$ for (in-situ) corrections applied during the measurement. Based on this analysis of correction components (Table II) and discussions in upcoming sections, we will provide rationalization for further down-selection of protocol parameters for ORR activity measurements.

Measurement protocols.-As we briefly mentioned in the introduction, in addition to the operating conditions, one of the causes for the scatter in SA values are the variations in measurement protocol used in the literature between research groups. In the following sections, we discuss the impact of protocol parameters such as potential scan rate, scan direction and potential range. At the end of each subsection, we down-select and define a preferred protocol based on the systematic experimental study of various parameters that affect the accuracy and reproducibility of the measured ORR activity. We have studied both poly-Pt and Pt/HSC (prepared using the RAD technique) since the impact of protocol parameters may be expected to be somewhat different for a thin film catalyst layer in contrast to the relatively smooth surface of bulk poly-Pt. We would like to emphasize that, for the case of $\mathrm{Pt} / \mathrm{HSC}$, the ink dispersion, film fabrication technique and ensuing film properties will have a critical impact on the measured ORR activity; this aspect will be addressed in Part II of this paper.

Break-in/conditioning.-Prior to evaluating poly-Pt disk or $\mathrm{Pt} / \mathrm{HSC}$ film deposited on a GC tip, it is necessary to conduct a 'breakin' or conditioning procedure to obtain peak ECA and ORR activity that is associated with maximum catalyst utilization. Conditioning procedures apparently result in oxidation/removal of surface impurities and the formation of a stable re-organized surface on which reproducible measurements can be conducted. Early half-cell electrochemical studies on $\mathrm{Pt}$ wires in electrolytes included cycling the working electrode repeatedly to various potentials or even holding at $\mathrm{O}_{2}$ evolution potentials to obtain a clean reproducible $\mathrm{CV}$ and high ORR activity. ${ }^{12,69,85-87}$ Conditioning procedures are also commonly implemented in PEMFCs; the conditioning protocol for PEMFCs involves high/low potentials holds and potential cycling under operating conditions where humidified air flows over the cathode and hydrogen over the anode. ${ }^{88}$

RDE literature typically do not elaborate on the details of conditioning protocols or justification for the selected protocol but merely recommend repetitive potential cycling until the $\mathrm{CV}$ under $\mathrm{N}_{2}$ or $\mathrm{O}_{2}$ becomes stable. ${ }^{86,89}$ Figure 11a illustrates the gradual evolution of the $\mathrm{CV}$ profile as the number of $500 \mathrm{mV} / \mathrm{s}$ cycles advances to 50 (4 min). As we approach the 50th cycle, we observe the stabilization of the signature $\mathrm{H}_{\text {UPD }}$ and oxide features indicating completion of conditioning. Our choice of a scan rate of $500 \mathrm{mV} / \mathrm{s}$ is based on extensive studies that point to the number of cycles being a stronger accelerant for conditioning rather than the total duration. It should be mentioned that scan rates in the range $100-500 \mathrm{mV} / \mathrm{s}$ produce similar outcomes but require different durations. Figure $11 \mathrm{~b}$ shows the change in ORR $I-V$ curve profiles for poly-Pt before (black) and after (red) conditioning; the profile in the kinetic, mixed, and limiting current regimes have 

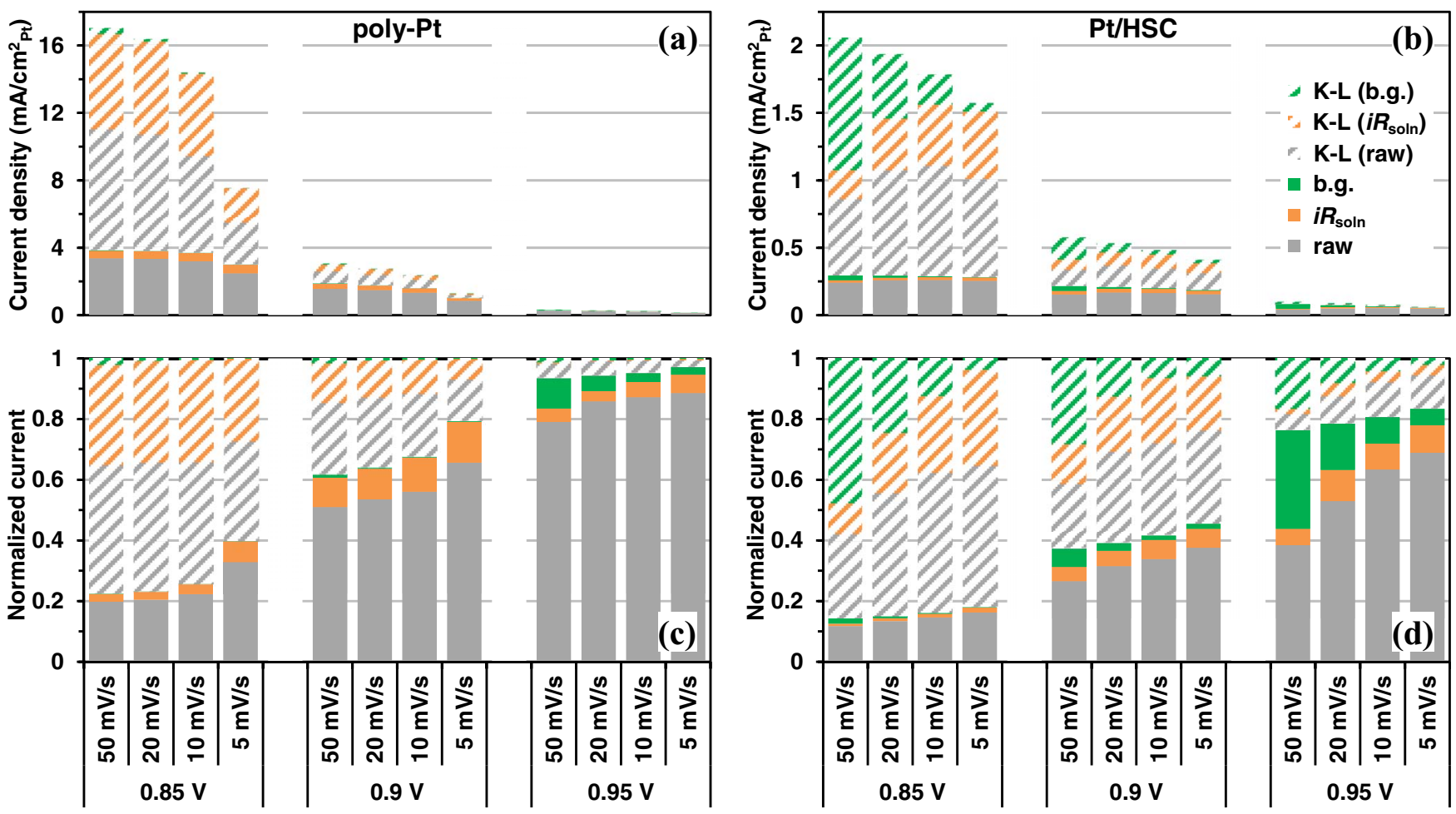

Figure 10. Analysis of contributions from $i R_{\text {soln }}$, b.g. currents and K-L corrections in kinetic currents for (a) poly-Pt and (b) Pt/HSC and contributions normalized to the kinetic current for (c) poly-Pt and (d) Pt/HSC. Breakdown presented as a function of 4 different scan rates (50, 20, 10 and $5 \mathrm{mV} / \mathrm{s})$ and $3 \mathrm{different}$ potentials $(0.85,0.9,0.95 \mathrm{~V})$ as denoted in the plot.

evolved and stabilized after conditioning. The SA of poly-Pt at $0.9 \mathrm{~V}$ ( $20 \mathrm{mV} / \mathrm{s}$, anodic sweep) rises from $\sim 0.6$ to $2.9 \mathrm{~mA} / \mathrm{cm}^{2}{ }_{\mathrm{Pt}}$ as a result of the conditioning process.
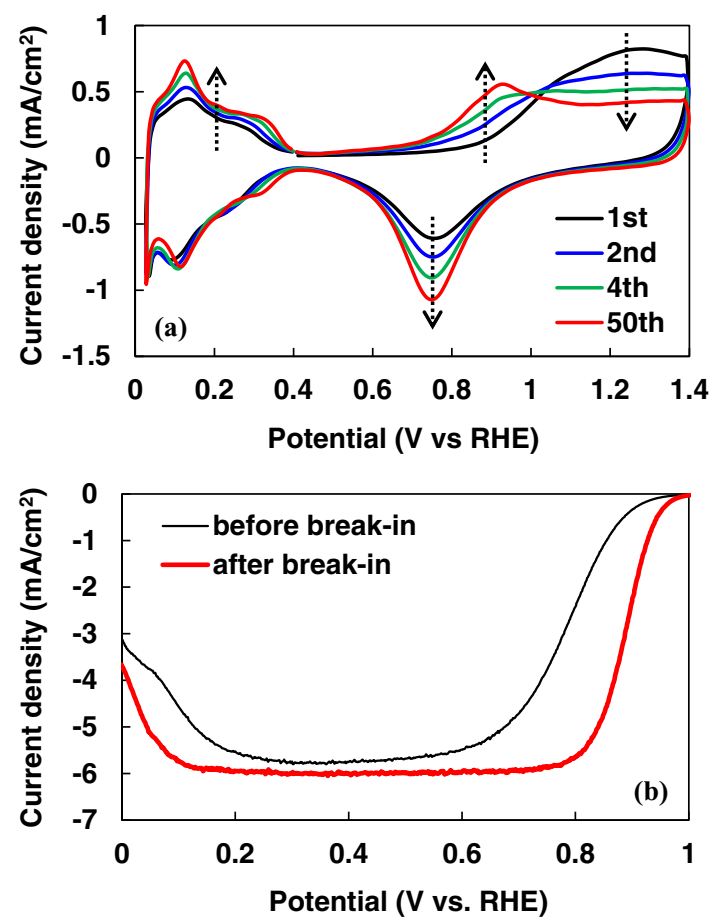

Figure 11. Effect of conditioning for poly-Pt: (a) CVs under $\mathrm{N}_{2}$ during conditioning $(0 \mathrm{rpm})$, (b) ORR $I-V$ curves before and after the conditioning $(20$ $\mathrm{mV} / \mathrm{s}, 1600 \mathrm{rpm},-0.01$ to $1.0 \mathrm{~V}$, anodic sweep, $i R_{\text {soln }}$ and b.g. corrected). All measurements conducted in $0.1 \mathrm{M} \mathrm{HClO}_{4}$.
The choice of upper potential may partly account for the variation in reported SA for poly-Pt electrodes in the literature in addition to differences in surface preparation methods such as mechanical polishing, flame annealing ${ }^{21,30}$ or inductive heating. ${ }^{59}$ We evaluated conditioning protocols for several defined upper potentials; cycling to an upper potential of $1.0 \mathrm{~V}$ for poly-Pt resulted in incomplete conditioning as observed in the green curve in Fig. 12a. On the other hand, cycling to $1.2 \mathrm{~V}$ or $1.4 \mathrm{~V}$ for 50 cycles appears to oxidize/remove certain contaminants from the surface resulting in a stable CV $(0.025-1.0 \mathrm{~V}, 20$ $\mathrm{mV} / \mathrm{s}$ ) with well-resolved characteristic pseudo-capacitive crests. For $\mathrm{Pt} / \mathrm{HSC}$, the upper potential was limited to $1.2 \mathrm{~V}$ to minimize carbon corrosion while still achieving conditioning as depicted in Fig. $12 \mathrm{~b}$.

Based on the above studies, we arrived at a measurement protocol for conditioning/break-in that is summarized with numerical details and a graphical representation in Table III. This conditioning protocol has been used as a standard for all the ORR activity characterization studies reported in Part I and II of this manuscript. We would like to point out, as a caveat, that although this protocol has been found to be satisfactory for several $\mathrm{Pt} / \mathrm{C}$ catalysts, some modifications may be necessary for Pt-alloy/C, unsupported Pt-alloy catalysts, $\mathrm{Pt}$ /graphitized carbon blacks, etc. In the case of Pt-alloys, if the catalyst has not been pre-leached, the base metal may dissolve and enter into the electrolyte as conditioning proceeds; this necessitates replacement of the electrolyte with fresh acid before final measurements are conducted. Likewise, certain Pt/graphitized carbons and heat-treated catalysts may be more hydrophobic and require increased number of conditioning cycles before they approach their peak ECA utilization and ORR activity.

ECA.-CVs conducted under an inert atmosphere provide us with at least four diagnostics that are essential for the complete characterization of catalysts in RDE studies. The primary diagnostic is the ECA extracted from the area under the $\mathrm{H}_{\text {UPD }}$ peaks-this area corresponds to $\mathrm{Pt}$ active sites that are connected both electronically and protonically and hence available for participation in reaction. A secondary diagnostic relates to the location of the onset of surface oxide 

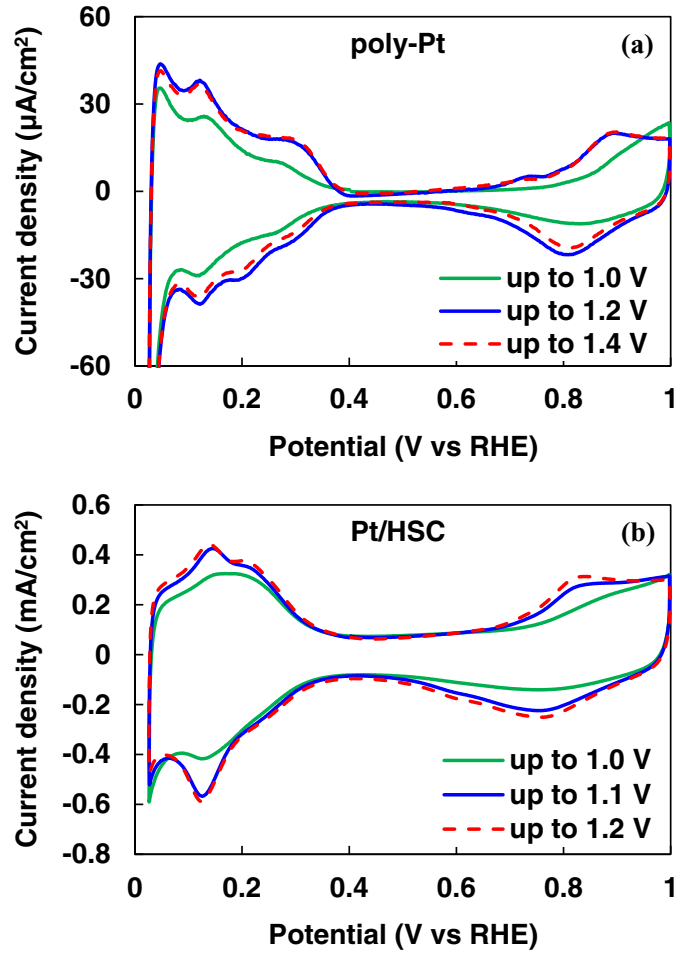

Figure 12. Effect of upper potential on electrode conditioning monitored using CVs after the conditioning process: (a) poly-Pt, (b) Pt/HSC. Final CVs after the conditioning measured in $0.1 \mathrm{M} \mathrm{HClO}_{4}$ under the following conditions: 0 $\mathrm{rpm}, 20 \mathrm{mV} / \mathrm{s}, 0.025-1.0 \mathrm{~V}$.

formation on Pt as well as the area under the oxide formation and reduction peaks. A positive shift in the onset of surface oxide formation has been correlated to the oxophobic nature of the surface of larger Pt nanoparticles $;^{90}$ it has also been correlated with Pt-alloys that exhibit improved ORR activity. ${ }^{29,46,91-96}$ Thirdly, peaks corresponding to anion adsorption from impurities may overlap with the $\mathrm{H}_{\mathrm{UPD}}$ and also cause a negative shift of the onset of oxides. ${ }^{10,29,35,47,51-54,58-65,97}$ Lastly, the so-called double layer regime provides capacitance information associated with $\mathrm{Pt}$ and/or carbon black and an estimate of the roughness factor. ${ }^{52,98}$ The impact of rotation speed, voltage range and scan rate on the ECA are discussed below.

ECA.- $-H_{U P D}$ - - Rotation speed.- It is noteworthy that the effect of rotation speed is negligible over most of the potential range except in the vicinity of $\mathrm{H}_{2}$ evolution potentials. As the rotation speed is increased, dissolved $\mathrm{H}_{2}$ close to the catalyst surface is swept away lowering the concentration of $\mathrm{H}_{2}$; this causes the onset of $\mathrm{H}_{2}$ evolution to shift toward positive potentials partially masking the $\mathrm{H}_{\text {UPD }}$ peaks and resulting in a lower estimate of the charge (ECA) that is typically measured to the inflection point $(\sim 0.05 \mathrm{~V})$. In our studies, a $13 \%$

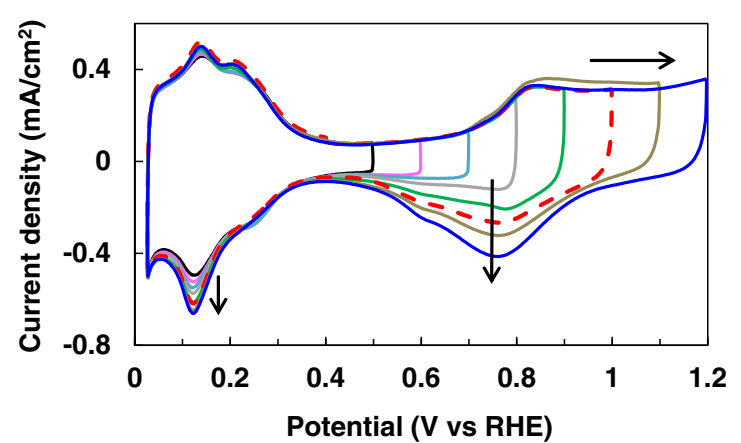

Figure 13. CVs under $\mathrm{N}_{2}$ on Pt/HSC conducted between a fixed lower potential of $0.025 \mathrm{~V}$ to systematically increasing upper potentials. CVs conducted in $0.1 \mathrm{M} \mathrm{HClO}_{4}$ at $0 \mathrm{rpm}$. ECA estimated from $\mathrm{H}_{\text {UPD }}$ charge calculated from the $\mathrm{CV}$ profiles between $\sim 0.05 \mathrm{~V}$ and $\sim 0.4 \mathrm{~V}$.

decrease in ECA was observable as rotation speed was raised from 0 to $2500 \mathrm{rpm}$ for poly-Pt. It is interesting to note that a phenomenon has been reported in MEAs of PEMFCs where a high flow of $\mathrm{N}_{2}$ that sweeps away cross-over and generated $\mathrm{H}_{2}$ at the working electrode produces a similar effect as high rotation speed in RDE. ${ }^{99-101}$ Based on this understanding, all $\mathrm{CV}$ measurements under $\mathrm{N}_{2}$ were conducted at $0 \mathrm{rpm}$ in this work.

ECA.- $H_{U P D}$ - - Potential range.- When measuring CVs under nitrogen, we typically conduct 3 sweeps or cycles starting from the double layer region $(\sim 0.4 \mathrm{~V})$ and record the stabilized third sweep. Figure 13 shows $\mathrm{CV}$ s conducted in the range $0.025 \mathrm{~V}$ to upper potentials ranging from $0.50-1.2 \mathrm{~V}$. One can observe that the charge related to oxide formation/reduction increases with increasing upper potential and this in turn affects the $\mathrm{H}_{\text {UPD }}$ peaks. The difference in $\mathrm{H}_{\mathrm{UPD}}$ area for sweeps conducted in the range $0.025-0.5 \mathrm{~V}$ versus $0.025-1.2 \mathrm{~V}$ is $\sim 2 \%\left(\sim 98-102 \mathrm{~m}^{2} / \mathrm{g}_{\mathrm{Pt}}\right)$ and can be attributed to an incomplete reduction of oxides or a change/reorganization in the surface layer of $\mathrm{Pt}$ on which hydrogen adsorbs. The red dashed CV in Fig. 13 represents the protocol that we have employed throughout this study as detailed in Table IV.

ECA.- $H_{U P D}$ - Scan rate.-The result of a higher scan rate on CVs is primarily an increase in pseudo-capacitive currents as evident in Fig. 14. In order to be able to observe shifts in the onset of the pseudocapacitive peaks, it is necessary to normalize the current to the scan rate to obtain the capacitance profile as illustrated in the inset of Fig. 14 (The CVs were intentionally left uncorrected for $i R_{\text {soln }}$ ). We observe small shifts in the $\mathrm{H}_{\text {UPD }}$ peaks for scan rates above $20 \mathrm{mV} / \mathrm{s}$. These peak shifts disappear and all the capacitance curves are superimposed when the CVs are corrected for $i R_{\text {soln }}$ (not shown). Essentially, $i R_{\text {soln }}$ has a significant impact on the $\mathrm{CV}$ only at relatively high scan rates when the currents are large. At low catalyst loadings (and poly-Pt), since pseudo-capacitive currents are extremely low ( $\mu \mathrm{A}$ range), $i R_{\text {soln }}$ can be neglected; however, at low loadings, the onset of $\mathrm{H}_{2}$ evolution

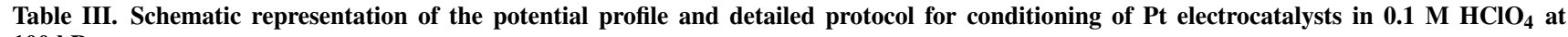
$100 \mathrm{kPa}$.

Potential Profile

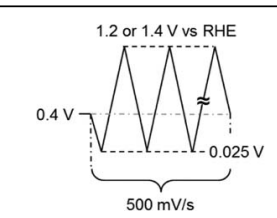

Protocol Parameters

$\begin{array}{cc}\text { Gas } & \mathrm{N}_{2} \\ \text { Temperature }\left({ }^{\circ} \mathrm{C}\right) & 23 \\ \text { Rotation Rate }(\mathrm{rpm}) & 1600-2500 \\ \text { Potential Range (V vs. RHE) } & 0.025-1.2 \text { or } 1.4 \\ \text { Scan Rate }(\mathrm{mV} / \mathrm{s}) & 500 \\ \text { Potential Cycle Number } & 50-100\end{array}$




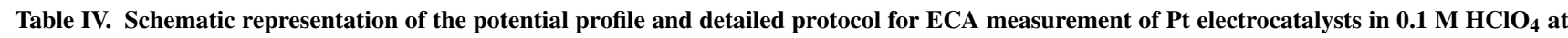
$100 \mathrm{kPa}$.

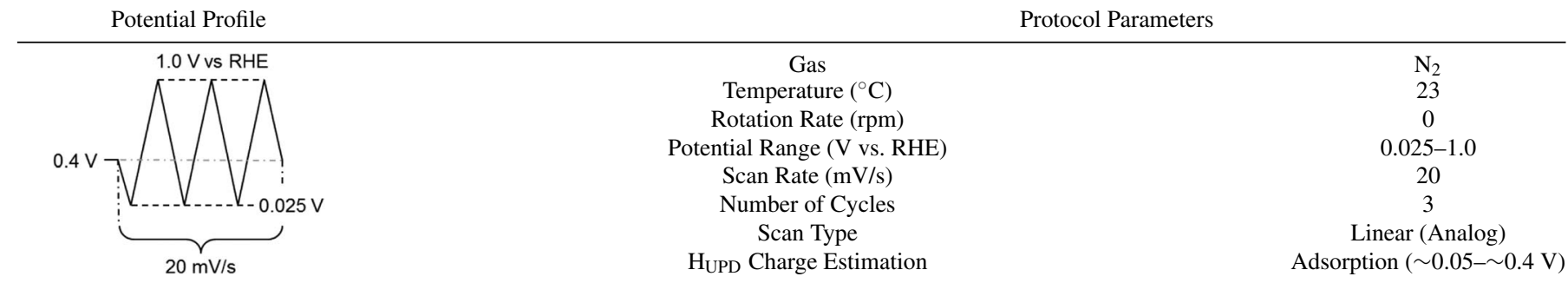

shifts toward positive potentials leading to an underestimation of the $\mathrm{H}_{\text {UPD }}$ charge and ECA. The red dashed CV in Fig. 14 at $20 \mathrm{mV} / \mathrm{s}$ corresponds to the application of the protocol that we have employed in this study as detailed in Table IV. Based on the above studies of potential range and scan rate, we arrived at a test protocol for ECA measurements using $\mathrm{H}_{\mathrm{UPD}}$ charge that is summarized with a graphical representation and related numerical details in Table IV.

ECA.-CO stripping voltammetry.-CO stripping measurements are often invoked in the literature when the alloying element $(\mathrm{Ru}, \mathrm{Co}, \mathrm{Ni}$, etc) on the catalyst surface smears or distorts the $\mathrm{H}_{\text {UPD }}$ peaks or when protons interact with the catalyst support (e.g. $\mathrm{WO}_{\mathrm{x}}$ ) producing peaks that are unrelated to the $\mathrm{H}_{\text {UPD }}$ and hence ECA..$^{32,92,93,102,103}$ In addition, CO stripping allows us to bypass the issues related to the inflection point that transitions into $\mathrm{H}_{2}$ evolution. ${ }^{104}$ Experimentally, it is necessary to ensure complete coverage of $\mathrm{CO}$ on Pt surface by allowing a sufficiently long purge time; residual $\mathrm{CO}$ in the electrolyte has to be subsequently eliminated with a $\mathrm{N}_{2}$ purge prior to carrying out $\mathrm{CO}$ stripping. The purge time is a function of $\mathrm{CO}$ flow rate, cell volume, etc. We evaluated several protocols and found that a hold potential under $\mathrm{CO}$ flow of $0.05-0.10 \mathrm{~V}$ for a period of $15 \mathrm{~min}$ was sufficient to obtain the peak $\mathrm{CO}$ stripping area. Figure 15 illustrates an example of CO stripping on Pt/HSC electrocatalyst that was held at $0.10 \mathrm{~V}$ for 15 min under $\mathrm{CO}$ and subsequently purged with $\mathrm{N}_{2}$ for $30 \mathrm{~min}$. In the first sweep (CO stripping), we observe capacitive currents until $\sim 0.6$ $\mathrm{V}$ followed by the emergence of a $\mathrm{CO}$ stripping peak in the voltage range $\sim 0.7-1.0 \mathrm{~V}$. If the $\mathrm{CO}$ has been completely oxidized from the Pt surface, the second sweep should resemble a typical CV under $\mathrm{N}_{2}$. To confirm that the electrolyte has indeed been purged of $\mathrm{CO}$, a final third sweep is recommended. In order to obtain the CO stripping

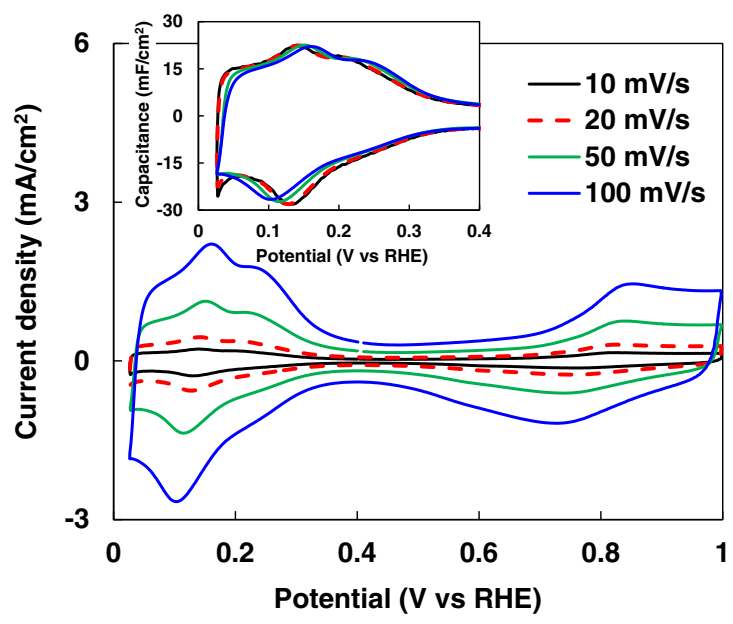

Figure 14. CVs under $\mathrm{N}_{2}$ on $\mathrm{Pt} / \mathrm{HSC}$ catalysts at $10-100 \mathrm{mV} / \mathrm{s}$. CVs conducted in $0.1 \mathrm{M} \mathrm{HClO}_{4}$ at $0 \mathrm{rpm}$ without $i R_{\text {soln }}$ correction. Current normalized to scan rate plotted in inset. charge, the second sweep is subtracted from the first and the residual area integrated. The ratio of $\mathrm{CO}$ stripping charge to $\mathrm{H}_{U P D}$ charge was found to be $1.8-1.9$ for poly-Pt and 2 for $\mathrm{Pt} / \mathrm{HSC}$ catalyst. CO oxidation is a $2 \mathrm{e}^{-}$process $\left(\mathrm{CO}+\mathrm{H}_{2} \mathrm{O} \rightarrow \mathrm{CO}_{2}+2 \mathrm{H}^{+}+2 \mathrm{e}^{-}\right)^{105-107}$ and since our experimentally determined ratio of $\mathrm{CO}$ stripping charge to $\mathrm{H}_{\mathrm{UPD}}$ charge is $\sim 2$, it implies one $\mathrm{CO}$ molecule adsorbed per $\mathrm{Pt}$ atom. Thus, the difference between the calculated ECAs using the CO stripping charge and $\mathrm{H}_{\mathrm{UPD}}$ charge does not appear to be significant enough to affect the measured ECA.

ORR activity.-The ORR activity of a catalyst can be fundamentally expressed as the product of the number of active sites and turnover frequency. A measure of the ORR activity described as the exchange current density $\left(i_{0}\right)$ can be obtained by extrapolating $I-V$ Tafel plots over several orders of magnitude to the oxygen reversible potential $\left(E_{\text {rev }}\right)$. However, extrapolation of the Tafel slope is susceptible to significant errors and produces multiple values depending on the potential regime selected. ${ }^{108}$ A practical and conventionally accepted representation of catalyst activity is the current density per Pt surface area at $0.9 \mathrm{~V}$ and $100 \mathrm{kPa} \mathrm{O}_{2} \cdot{ }^{4,5,26,31,33,35,95,109-111}$ Obvious reasons for the selection of $0.9 \mathrm{~V}$ are: i) the OCV of Pt in acid electrolytes is about $1 \mathrm{~V}$, ii) the ORR currents at $0.9 \mathrm{~V}$ are small enough that they may be expected to have negligible $i R_{\text {soln }}$ and $i R$ catalyst layer as well as complete participation of all the active sites, iii) the ORR currents are large enough in comparison to the reverse currents (e.g. Pt dissolution, carbon corrosion and impurities), iv) the magnification of errors in $i_{\mathrm{k}}$ that have their source in raw current measurements are minimized when the potential at which ORR activity is reported correspond to the range $\left(0.1<i / i_{\mathrm{d}}<0.5\right){ }^{30,84}$

It is well-known that a higher oxide coverage on the Pt surface suppresses the ORR kinetics. ${ }^{10,30,79,80,111-116}$ Moreover, kinetic data acquired at a fixed scan rate, for instance, cannot be transformed to

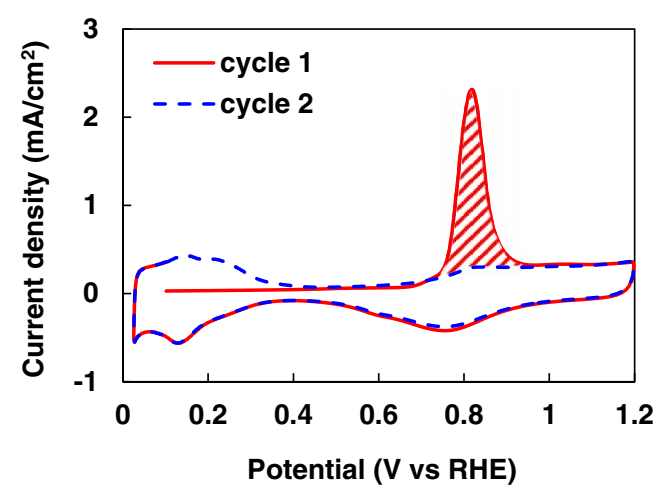

Figure 15. CO stripping voltammogram for $\mathrm{Pt} / \mathrm{HSC}$ catalyst in $\mathrm{N}_{2}$-purged 0.1 $\mathrm{M} \mathrm{HClO}_{4}$ at $20 \mathrm{mV} / \mathrm{s}$ : first curve obtained after saturation of Pt surfaces with CO (solid red line), second sweep (blue dotted line), third sweep identical to second and not shown for clarity. 


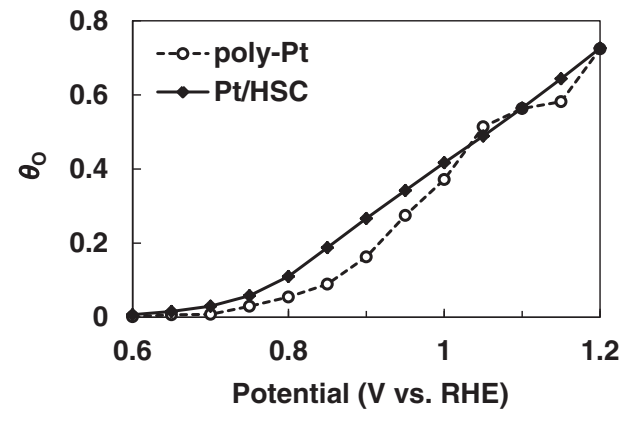

Figure 16. Potential dependence of $\mathrm{O}$ coverage on poly-Pt in $0.1 \mathrm{M} \mathrm{HClO}_{4}$ estimated from anodic sweeps under $\mathrm{N}_{2}$ at $20 \mathrm{mV} / \mathrm{s}$.

another scan rate for the purposes of comparison. The difficulty lies in the variable coverage of mixed surface oxide species ( $\mathrm{PtOH}, \mathrm{PtO}$, etc., on the Pt surface that are a function of both potential and time. ${ }^{117-119}$ In the oxide formation regime, the initial growth of surface oxides is a fast process; this is followed by a slow logarithmic growth over long periods of time via the 'place-exchange mechanism'. The magnitude of $\theta_{\mathrm{O}}$ between $0.6 \mathrm{~V}$ and varying upper potentials is illustrated in Fig. 16 (assuming PtO) for both poly-Pt and Pt/HSC. The oxide coverage $\left(\theta_{\mathrm{O}}\right)$ was estimated from the ratio of the oxide formation $\left(2 \mathrm{e}^{-}\right.$ process) charge to the $H_{U P D}$ charge. ${ }^{119-122}$ Since ORR kinetics are studied in the voltage range $0.6-1.0 \mathrm{~V}$, oxide species are formed and stripped during each sweep and the measured ORR activity, e.g., 0.9 $\mathrm{V}$, is dependent on the history of the catalyst surface and specifically the oxide coverage immediately prior to the measurement. Another factor that affects the measured ORR activity arises from trace impurities in the electrolyte that are drawn toward the electrode and adsorb on Pt. The measured ORR activity of poly-Pt and Pt/C electrocatalysts is exceptionally sensitive to measurement protocol parameters such as the scan direction (anodic or cathodic), potential range, and scan rate. Thus efforts to standardize the ORR measurement protocol with careful selection based on a comprehensive study are warranted to enable facile inter-lab comparison of results and are addressed here.

ORR activity.-Scan direction and potential range.-The effect of scan direction on the ORR $I-V$ curves is inextricably entwined with the effect of potential range and scan rate. The effect of scan direction for a fixed potential range $(-0.01$ to $1.0 \mathrm{~V})$ and two scan rates of 5 and $20 \mathrm{mV} / \mathrm{s}$ are shown in Fig. 17. The kinetic currents for anodic sweeps are consistently found to be higher than that for cathodic sweeps: for poly-Pt at $20 \mathrm{mV} / \mathrm{s} i_{\mathrm{k} \_ \text {anodic }}=3.6 i_{\mathrm{k} \_ \text {cathodic }}$ while at $5 \mathrm{mV} / \mathrm{s} i_{\mathrm{k} \_ \text {anodic }}$ $=5.3 i_{\mathrm{k} \_ \text {cathodic }}$, for $\mathrm{Pt} / \mathrm{HSC}$ at $20 \mathrm{mV} / \mathrm{s} i_{\mathrm{k} \_ \text {anodic }}=2 i_{\mathrm{k} \_ \text {cathodic }}$ while at 5 $\mathrm{mV} / \mathrm{s} i_{\mathrm{k} \_ \text {anodic }}=2.4 i_{\mathrm{k} \_ \text {cathodic }}$. This trend is a reflection of the fact that the sweep begins in a regime where the Pt surface is oxide-free and subsequently builds up as the potential proceeds from the reducing to oxidizing potentials. The inset of Fig. 17 illustrates the correlation

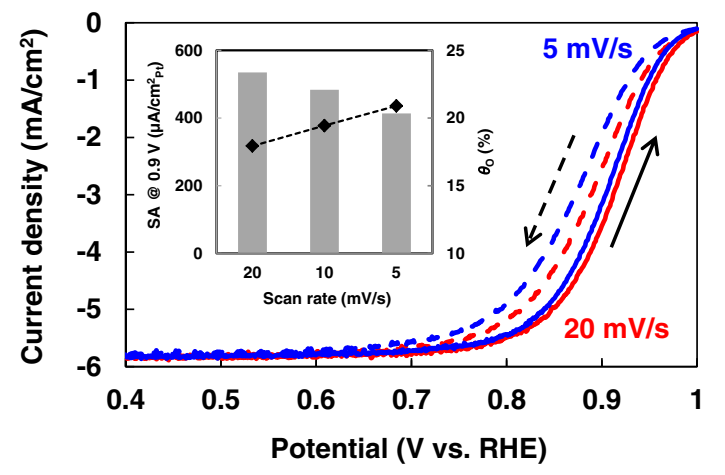

Figure 17. Effect of scan direction for Pt/HSC ORR $I-V$ curves at 5 and 20 $\mathrm{mV} / \mathrm{s}$ in $0.1 \mathrm{M} \mathrm{HClO}_{4}(-0.01$ to $1.0 \mathrm{~V})$. Inset shows the effect of scan rate (anodic sweep) on the SA at $0.9 \mathrm{~V}$ along with percentage $\mathrm{O}$ coverage on Pt. (a)
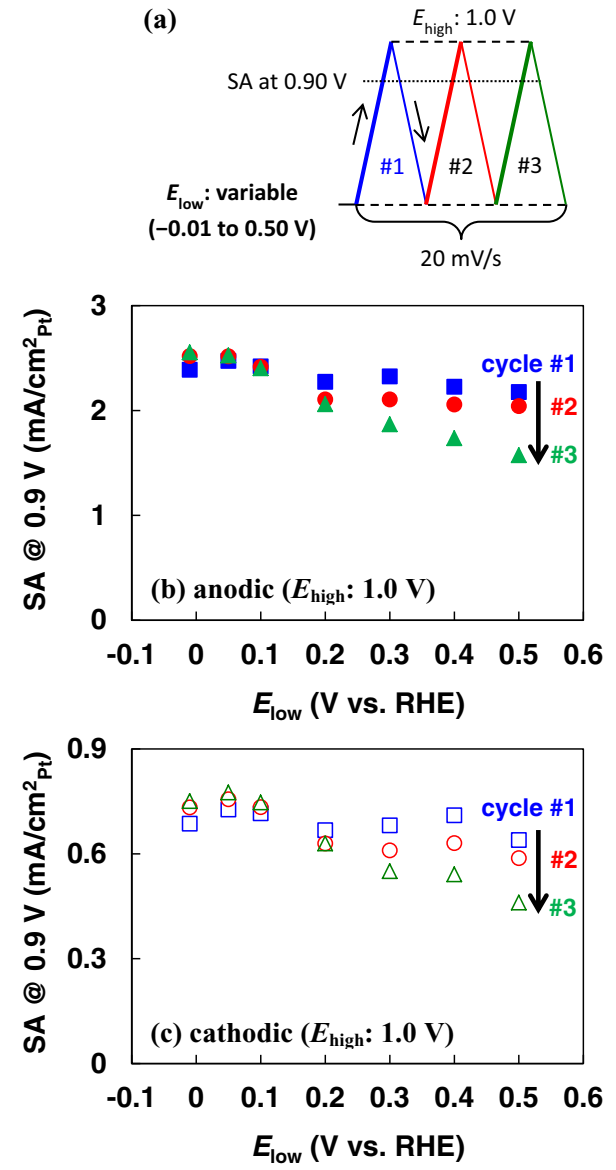

Figure 18. (a) Potential profiles applied to evaluate the effect of $E_{\text {low }}$ on the $\mathrm{SA}$ at $0.9 \mathrm{~V}$ in $0.1 \mathrm{M} \mathrm{HClO}_{4}\left(E_{\text {high }}: 1.0 \mathrm{~V}\right.$, b.g. and $i R_{\text {soln }}$ corrected). SA of poly-Pt electrode as a function of $E_{\text {low }}$ for (b) 3 anodic sweep profiles and (c) 3 cathodic sweep profiles.

between the SA and oxide coverage which was extracted from CVs under $\mathrm{N}_{2}$ conducted using an identical protocol as the ORR $I$ - $V \mathrm{~s}$; these trends are in agreement with literature. ${ }^{10,30,79,111-116,122}$

The potential window over which the $I$ - $V$ curves are measured has a noticeable effect on the measured ORR activity and reproducibility at $0.9 \mathrm{~V}$. To study the effect of lower potential limit in the range -0.01 to $0.6 \mathrm{~V}$, we pinned the scan rate at $20 \mathrm{mV} / \mathrm{s}$ and upper potential $\left(E_{\text {high }}\right)$ at $1.0 \mathrm{~V}$ as shown in the potential profile of Fig. 18a. Figure 18b depicts the effect of lower potential $\left(E_{\text {low }}\right)$ on the SA for three consecutive sweeps in the anodic direction; as the $E_{\text {low }}$ is raised from $-0.01 \mathrm{~V}$ to $0.6 \mathrm{~V}$, the surface oxide coverage at the beginning of each sweep is higher resulting in lower measured SA. When sweeps are started at potentials $>0.1 \mathrm{~V}$, the Pt surface is not completely reduced between sweeps leading to a buildup of oxides with time over three sweeps and a concomitant loss in measured SA with every consecutive cycle (\#1, \#2, \#3). Conversely, when start potentials are confined to the range $0.01 \mathrm{~V}$ to $0.10 \mathrm{~V}$, the sweeps start with an oxide free surface leading to high reproducibility for each of three consecutive sweeps. Figure $18 \mathrm{c}$ shows the same trend for the SA measured in the cathodic direction as was observed in the anodic direction although the magnitude of SA is lower by a factor of $\sim 3$. It is noteworthy that although a controlled potential history is a necessary condition, it is not sufficient, in that, $E_{\text {low }} \leq 0.1 \mathrm{~V}$ that results in a complete removal of oxides is required to obtain reproducible SA in cathodic direction as well. Based on these observations of high, reproducible activities for start potentials in the range -0.01 to $0.1 \mathrm{~V}$, we down-select $E_{\text {low }}$ to $-0.01 \mathrm{~V}$. Furthermore, we evaluated the effect of $E_{\text {high }}$ on SA in the range 1.0-1.2 V for a fixed lower potential of $-0.01 \mathrm{~V}$ and $20 \mathrm{mV} / \mathrm{s}$. Unsurprisingly, the 

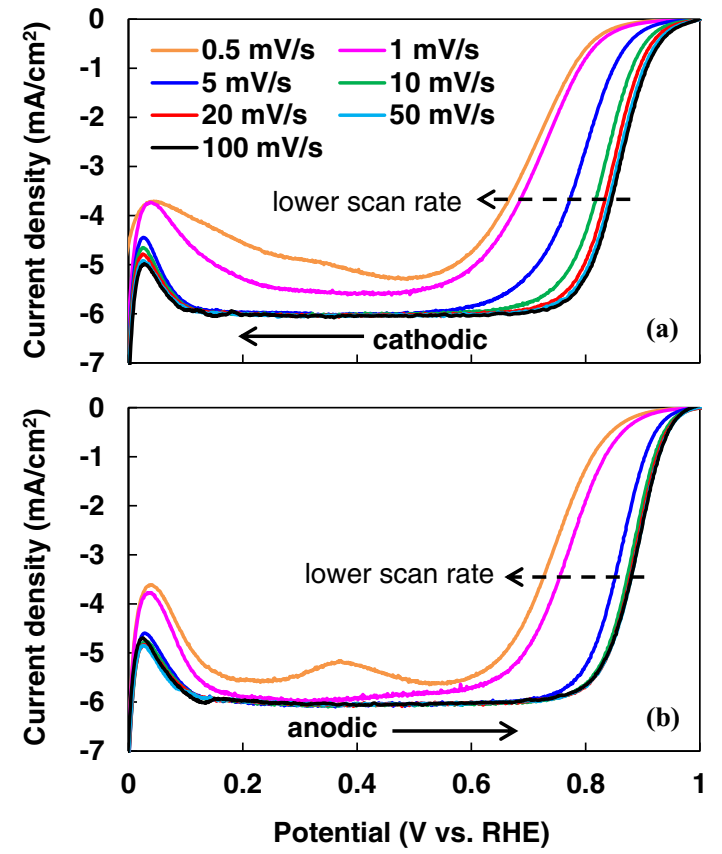

Figure 19. ORR $I-V$ curves of poly-Pt in $0.1 \mathrm{M} \mathrm{HClO}_{4}$ at $0.5-100 \mathrm{mV} / \mathrm{s}$ without b.g. correction: (a) cathodic scan and (b) anodic scan. Sweeps were initiated from $-0.01 \mathrm{~V}$ and swept anodically to $1.0 \mathrm{~V}$ followed by a cathodic sweep to $-0.01 \mathrm{~V}$ under the conditions: $1600 \mathrm{rpm}, i R_{\text {soln }}$ corrected.

SA is unchanged irrespective of $E_{\text {high }}$ for anodic sweeps since all the oxide generated at the upper potentials are completely reduced at $E_{\text {low }}$ of $-0.01 \mathrm{~V}$. For sweeps performed in the cathodic direction, as we raise $E_{\text {high }}$ from $1.0 \mathrm{~V}$ to $1.2 \mathrm{~V}$, the oxide coverage is expectedly higher leading to lower measured SAs (not shown). Based on these results, we down-select the anodic scan direction that is initiated from a well-defined oxide-free surface and proceeds toward OCV.

ORR activity.-Scan rate.- In order to investigate the effect of scan rate we confine our studies in the potential range -0.01 and $1.0 \mathrm{~V}$ based on our discussion in the previous section. Figure 19 illustrates the ORR $I-V$ curves for poly-Pt in the range $0.5-100 \mathrm{mV} / \mathrm{s}$ as labeled; the $I-V$ profile in the kinetic and mixed regime declines systematically with a decrease in scan rate. Although the ORR $I$ - $V$ curves for poly-Pt fall in a narrow band for scan rates $\geq 10 \mathrm{mV} / \mathrm{s}$, a steep decrease is observed at scan rates $\leq 5 \mathrm{mV} / \mathrm{s}$. The $\%$ loss in SA for poly-Pt between $20 \mathrm{mV} / \mathrm{s}$ and $5 \mathrm{mV} / \mathrm{s}$ is $\sim 50 \%$ (Fig. 10a) while that for $\mathrm{Pt} / \mathrm{HSC}$ is only $\sim 25 \%$ (Fig. 10b). Since oxide formation is less pronounced on poly-Pt surface at most potentials (Fig. 16), this precipitous loss can only be ascribed to contamination of poly-Pt due to its low surface area. At even lower scan rates such as 0.5 and $1 \mathrm{mV} / \mathrm{s}$ (Fig. 19), we additionally observe a lowering of the limiting current as well as an anomalous feature that may be attributed to impurity anion adsorption and $\mathrm{H}_{2} \mathrm{O}_{2}$ production that preclude us from extracting reliable SA values. Furthermore, the surface oxide coverage is higher at low scan rates since the catalyst spends more time at oxide forming potential to further lower the SA as is also evident in the inset of Fig. 17. At higher scan rates $>20 \mathrm{mV} / \mathrm{s}$, the impact of b.g. correction on the SA increase factor at $0.9 \mathrm{~V}$ is significant for $\mathrm{Pt} / \mathrm{HSC}$ as shown previously in Table II. Based on these considerations of contamination, surface oxides at lower scan rates, and b.g. correction contributions at high scan rates, we can narrow down a preferred range of scan rates to $10-20 \mathrm{mV} / \mathrm{s}$. Therefore, we may further down-select the scan rate to $20 \mathrm{mV} / \mathrm{s}$ which is fairly common in the literature. , $29-33,50^{-}$

ORR activity.-Steady-state.-Practical PEMFCs are typically evaluated for performance using pseudo steady-state conditions and the question arises as to whether it is possible and reasonable to conduct similar measurements in RDE studies and identify the consequent
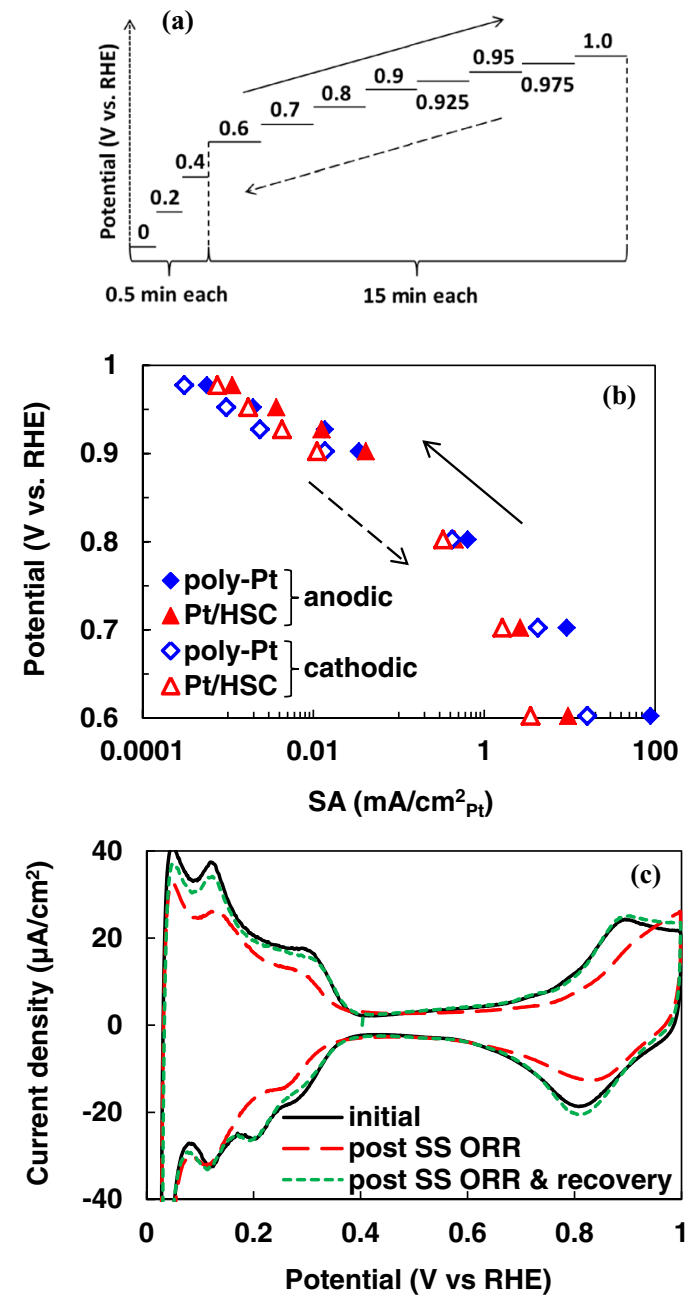

Figure 20. (a) Schematic representation of the ORR measurement protocol for the measurement of pseudo steady-state $I-V$ curves in $0.1 \mathrm{M} \mathrm{HClO}_{4}$, and, (b) ORR Tafel plots for poly-Pt and Pt/HSC catalysts. Electrodes held at each potential for $15 \mathrm{~min}$ with the exception of low potentials $\leq 0.4 \mathrm{~V}$ in the anodic and cathodic directions. (c) CVs under $\mathrm{N}_{2}$ : (i) initial, (ii) after the steady-state ORR activity measurements, and (iii) after conditioning (recovery) followed by the steady-state activity measurements.

advantages or repercussions. A schematic of the ORR protocol applied for the measurement of pseudo steady-state ORR I-V curves (15 $\mathrm{min} /$ point) in both the anodic and cathodic directions is presented in Fig. 20a. Figure 20b is plot of the resultant ORR $I-V$ curves based on averaging the data for the last 30 s of each 15 min potential hold. During each 15 min potential hold, the ORR currents initially decay rapidly followed by a slower rate; even after $15 \mathrm{~min}$, true steady-state is not achieved. It is remarkable that the currents exhibit hysteresis between the anodic and cathodic sweeps even under these pseudo steady-state conditions. The results of our pseudo steady-state studies agree qualitatively (but not quantitatively) with those reported for MEAs of PEMFCs where a similar decay in current during a potential hold as well as hysteresis is observed. ${ }^{100}$ The catalyst interface in MEAs of PEMFCs differ significantly from that in RDE; the catalyst layer of MEAs have $\mathrm{Pt} / \mathrm{C}$ and a thin film of ionomer with gas and water pores whereas the catalyst layer in RDE is flooded with acid. In RDE measurements under pseudo steady-state conditions, the flooded catalyst layer in perchloric acid is highly susceptible to trace impurities that adsorb from the electrolyte. CV features obtained at the end of the steady-state sweep (Fig. 20c) (shift in the onset of oxide formation) corroborate that the catalyst surface has indeed suffered poisoning. The original CV features were recovered after a conditioning 


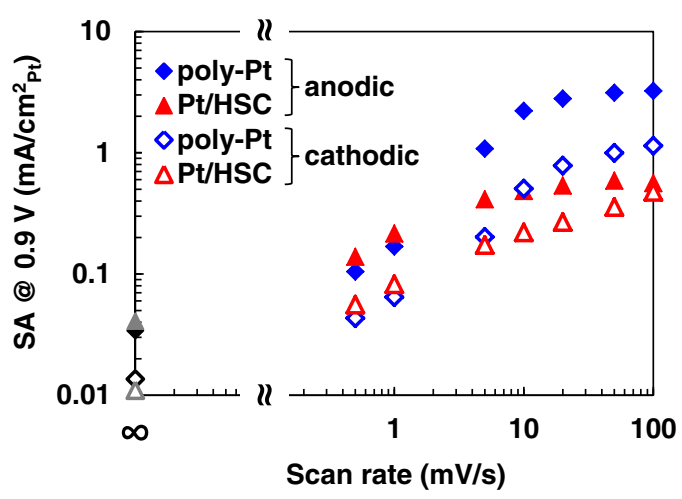

Figure 21. Effect of scan rate on the measured SAs for poly-Pt and $\mathrm{Pt} / \mathrm{HSC}$ in $0.1 \mathrm{M} \mathrm{HClO}_{4}$ in the range $0.5-100 \mathrm{mV} / \mathrm{s}$. Pseudo steady-state measurements (15 min/point) represented by black (poly-Pt) and gray (Pt/HSC) on the bottom left; the abscissa is split to include pseudo steady-state data markers at zero scan rate.

procedure was applied (potential cycles from 0.025 to $1.2 \mathrm{~V}$ at 500 $\mathrm{mV} / \mathrm{s}$ ). Additional findings not reported here indicate that the poisoning of the catalyst during steady-state current holds is more severe at lower loadings $\left(\mu \mathrm{g}_{\mathrm{Pt}} / \mathrm{cm}^{2}\right)$ of $\mathrm{Pt} / \mathrm{HSC}$ and poly-Pt. Thus it appears undesirable to acquire ORR kinetics under pseudo steady-state conditions in RDE systems.

The SA of poly-Pt and Pt/HSC extracted from Figs. 19 and 20 for various scan rates as well as steady-state measurements are summarized in Fig. 21. ORR currents are approximately two orders of magnitude lower under pseudo steady-state in contrast to that at 20 $\mathrm{mV} / \mathrm{s}$ (anodic sweep). Hysteresis in the ORR activity over the entire range of scan rates (including pseudo steady-state) between the anodic and cathodic sweeps for poly-Pt as well as Pt/HSC is also observed. Higuchi et al. ${ }^{89}$ have reported in their work using CFDE method that ORR $I$ - $V$ curves for anodic and cathodic scans exhibit negligible hysteresis at $0.5 \mathrm{mV} / \mathrm{s}$ suggesting that steady-state had been attained. The lack of agreement between the present study and that of Higuchi et al. ${ }^{89}$ could stem from impurities in their electrochemical system.

Based on the above discussion, it is evident that the slow scan rates result in significant contamination and high surface oxide coverage of the catalyst that manifests itself as a steep decrease in the measured ORR activity, severe hysteresis, anomalous features and attenuated limiting currents. The rate of change of SA is observed to plateau for scan rates in the range $10-50 \mathrm{mV} / \mathrm{s}$; as discussed previously, we have selected $20 \mathrm{mV} / \mathrm{s}$ as the scan rate for all experiments reported in this work (unless stated otherwise). Since the surface species $(\mathrm{PtOH}$, $\mathrm{PtO}$, etc.) and surface oxide coverage $\left(\theta_{\text {oxide }}\right)$ of $\mathrm{Pt}$ are not well defined, (with the exception of an over-simplified $\theta_{\mathrm{O}}$ vs. $E$ plot as in Fig. 16), it becomes challenging to convert data from a given scan rate and scan direction to another or normalize activity to scan rate.

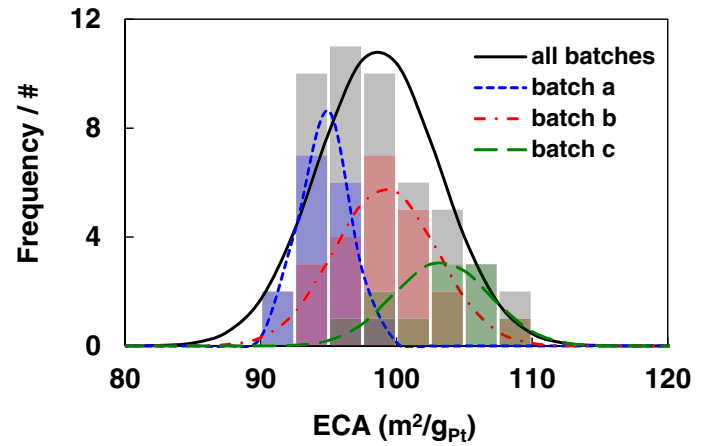

Figure 22. Gaussian distribution for the ECA of Pt/HSC electrocatalyst measured in $0.1 \mathrm{M} \mathrm{HClO}_{4}$ based on 49 independent sample electrodes using the ECA test protocol detailed in Table IV $\left(23^{\circ} \mathrm{C}, \mathrm{N}_{2}, 0 \mathrm{rpm}, 20 \mathrm{mV} / \mathrm{s}\right.$, 0.025-1.0 V). Gaussians for samples measured from each of the 3 catalyst batches also presented.

Acquisition of data at a defined scan rate and scan direction as well as potential window would allow facile comparison of data between labs. A test protocol for measurement of the ORR activity is summarized along with a graphical representation and associated numerical values detailed in Table V. This ORR activity protocol has been used as a standard for all the electrochemical activity characterization measurements reported in Part I and II of the manuscript.

Statistical reproducibility.-Electrocatalyst suppliers scale up their materials in batches that approach a few kg and verify batchto-batch quality by characterizing dry catalyst powders for BET, CO chemisorption, TEM and XRD but only sporadically report ORR activities. In order to verify the batch-to-batch variability of SA, we report activity measurements for 3 batches of TKK Pt/HSC electrocatalysts using the protocols defined in earlier sections.

A Normal or Gaussian distribution is conventionally invoked to obtain the mean and variance when the standard deviation of an entire population is known. In order to report valid standard deviations, it is necessary to evaluate sufficient number of samples from several inks. When the standard deviation of a population is not known and only 3-8 samples are evaluated as is conventional in the RDE literature, ${ }^{27,35,50,83}$ a ' $t$ ' distribution is the more appropriate choice. A ' $t$ ' distribution for a sample size of 50 approaches a normal distribution to within $2 \%$ for a $90 \%$ confidence interval (CI); for 20 samples, the ' $t$ ' distribution is within $5 \%$ for the same CI. Although it is not necessary to evaluate 20-50 independent RDE samples for every novel catalyst, it is desirable to do so when establishing benchmark ECA, SA and MA values for a baseline Pt/C catalyst. In Fig. 22, we demonstrate the reproducibility of the ECA values for Pt/HSC prepared using the RAD method with a Gaussian fit to the sample frequency, along with the Gaussians corresponding to 3 batches (a: 109-2471, b: 1010-2031,

Table V. Schematic representation of the potential profile and protocol for ORR activity measurement protocol of Pt electrocatalysts in $0.1 \mathrm{M}$ $\mathrm{HClO}_{4}$ at $100 \mathrm{kPa}$.

Potential Profile

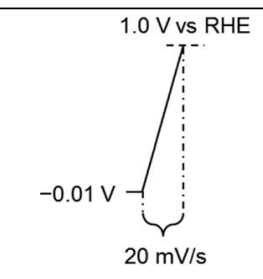

Protocol Parameters

$\begin{array}{cc}\text { Gas } & \mathrm{N}_{2} \text { or } \mathrm{O}_{2} \\ \text { Temperature }\left({ }^{\circ} \mathrm{C}\right) & 23 \\ \text { Rotation Rate }(\mathrm{rpm}) & 1600 \\ \text { Potential Range (V vs. RHE) } & -0.01 \text { to } 1.0 \text { (Anodic) } \\ \text { Scan Rate }(\mathrm{mV} / \mathrm{s}) & 20 \\ R_{\text {soln }} \text { Measurement Method } & i \text {-interrupter or EIS (HFR) } \\ i R_{\text {soln }} \text { Compensation } & \text { Positive Feedback } \\ \text { Background Correction } & i_{\mathrm{O}_{2}}-i_{\mathrm{N}_{2}}\end{array}$


c: 1010-6671) of catalyst powder from which they were prepared. The ECA based on the combined Gaussian for 49 independent samples is $99 \pm 5(5 \%) \mathrm{m}^{2} / \mathrm{g}_{\mathrm{Pt}}$; the corresponding SA and MA are $485 \pm 50$ $(10 \%) \mu \mathrm{A} / \mathrm{cm}^{2}{ }_{\mathrm{Pt}}$ and $477 \pm 42(9 \%) \mathrm{mA} / \mathrm{mg}_{\mathrm{Pt}}$. Bearing in mind the contribution of electrochemical measurement errors, the results reveal excellent batch-batch reproducibility of the TKK Pt/HSC catalyst.

\section{Conclusions}

Although RDE studies for screening the ORR activity of Pt based catalysts is widespread, the results are highly sensitive to impurity levels in the cell and electrolyte, protocols used for conditioning, ECA and ORR $I-V$ measurements as well as corrections for background currents and solution resistance. We have conducted extensive systematic studies on the evaluation of these factors on the measured ORR activity and arrived at reasonable protocols that will allow rapid screening of electrocatalysts and ensure a high degree of reproducibility. Poly-Pt is an excellent sensor of impurity levels such that obtaining an $\mathrm{SA}>2.0 \mathrm{~mA} / \mathrm{cm}^{2}\left(20 \mathrm{mV} / \mathrm{s}, 25^{\circ} \mathrm{C}, 100 \mathrm{kPa}, 0.1 \mathrm{M} \mathrm{HClO}_{4}\right)$ allows for the accurate determination of the ORR activity of Pt based catalysts. We have demonstrated the statistical reproducibility of ORR activity in our laboratory for poly-Pt and Pt/HSC using the protocols that have been outlined. The applicability of these protocols to verify reproducibility for several catalyst candidates in three independent laboratories has also been conducted, and will be reported elsewhere. The methodology and protocols developed in this study have been applied to investigate the effect of ink formulation and film fabrication parameters on the ORR activity of nanoparticle Pt/C catalysts in Part II of this work.

\section{Acknowledgments}

Shyam S. Kocha gratefully acknowledges funding from the U.S. Department of Energy, Fuel Cells Technologies Program under Contract No. DE-AC36-08-GO28308 to the National Renewable Energy Laboratory (NREL). Kazuma Shinozaki greatly acknowledges Prof. Kim Williams at Colorado School of Mines (CSM), Dr. Yu Morimoto, Mr. Tatsuya Hatanaka and Dr. Masaya Kawasumi at Toyota Central R\&D Labs., Inc. (TCRDL) for advice on his thesis work. Kazuma Shinozaki's stay at NREL and CSM was funded by TCRDL. We would also like to thank Dr. Svitlana Pylypenko of Colorado School of Mines for SEM images of poly-Pt.

\section{References}

1. D. Papageorgopoulos, Annu. Merit Rev. Proc. Fuel Cells (2014) http://www. hydrogen.energy.gov/pdfs/review14/fc000_papageorgopoulos_2014_o.pdf.

2. S. S. Kocha, in Polymer Electrolyte Fuel Cell Degradation, M. Mench, E. C. Kumbur, and T. N. Veziroglu, Editors, p. 89, Elsevier Inc. (2012).

3. A. Iiyama, K. Shinohara, S. Iguchi, and A. Daimaru, in Handbook of Fuel Cells: Advances in Electrocatalysis, Materials, Diagnostics and Durability, W. Vielstich, H. A. Gasteiger, and H. Yokokawa, Editors, p. 1090, Wiley, Chichester, UK (2009).

4. H. A. Gasteiger, S. S. Kocha, B. Sompalli, and F. T. Wagner, Appl. Catal. B Environ., 56, 9 (2005)

5. C. M. Zalitis, D. Kramer, and A. R. Kucernak, Phys. Chem. Chem. Phys., 15, 4329 (2013).

6. A. R. Kucernak and E. Toyoda, Electrochem. commun., 10, 1728 (2008).

7. N. Wakabayashi, M. Takeichi, M. Itagaki, H. Uchida, and M. Watanabe, J. Electroanal. Chem., 574, 339 (2005).

8. M. Itagaki, H. Hasegawa, K. Watanabe, and T. Hachiya, J. Electroanal. Chem., 557, 59 (2003).

9. A. J. Bard and L. R. Faulkner, Electrochemical Methods: Fundamentals and Applications., 2nd ed., John Wiley \& Sons, New York, (2000).

10. S. K. Zecevic, J. S. Wainright, M. H. Litt, S. L. Gojkovicć, and R. F. Savinell, J. Electrochem. Soc., 144, 2973 (1997).

11. R. J. Roethlein and H. J. R. Maget, J. Electrochem. Soc., 113, 581 (1966).

12. A. Damjanovic and V. Brusic, Electrochim. Acta, 12, 615 (1967).

13. D. Gilroy and B. E. Conway, Can. J. Chem., 46, 875 (1968).

14. A. J. Appleby and A. Borucka, J. Electrochem. Soc., 116, 1212 (1969).

15. A. J. Appleby, J. Electrochem. Soc., 117, 328 (1970).

16. K. J. Vetter and J. W. Schultze, J. Electroanal. Chem. Interfacial Electrochem., 34, 141 (1972).

17. D. A. J. Rand and R. Woods, J. Electroanal. Chem. Interfacial Electrochem., 47, 353 (1973).
18. M. Paucirova, D. M. Drazic, and A. Damjanovic, Electrochim. Acta, 18, 945 (1973).

19. H. Angerstein-Kozlowska, B. E. Conway, and W. B. A. Sharp, J. Electroanal. Chem. Interfacial Electrochem., 43, 9 (1973).

20. B. V. Tilak, B. E. Conway, and H. Angerstein-Kozlowska, J. Electroanal. Chem. Interfacial Electrochem., 48, 1 (1973).

21. P. N. Ross, J. Electrochem. Soc., 126, 78 (1979).

22. S. D. Fritts, D. Gervasio, R. L. Zeller III, and R. F. Savinell, J. Electrochem. Soc., 138, 3345 (1991)

23. H. Ye, J. A. Crooks, and R. M. Crooks, Langmuir, 23, 11901 (2007).

24. A. Ohma, K. Fushinobu, and K. Okazaki, Electrochim. Acta, 55, 8829 (2010).

25. T. Toda, H. Igarashi, and M. Watanabe, J. Electroanal. Chem., 460, 258 (1999).

26. K. Ke, K. Hiroshima, Y. Kamitaka, T. Hatanaka, and Y. Morimoto, Electrochim. Acta, 72, 120 (2012)

27. W. Sheng, S. Chen, E. Vescovo, and Y. Shao-Horn, J. Electrochem. Soc., 159, B96 (2012).

28. E. Toyoda, R. Jinnouchi, T. Ohsuna, T. Hatanaka, T. Aizawa, S. Otani, Y. Kido, and Y. Morimoto, Angew. Chem. Int. Ed. Engl., 52, 4137 (2013).

29. V. Stamenković, T. J. Schmidt, P. N. Ross, and N. M. Marković, J. Phys. Chem. B, 106, 11970 (2002)

30. K. J. J. Mayrhofer, D. Strmenik, B. B. Blizanac, V. Stamenkovic, M. Arenz, and N. M. Markovic, Electrochim. Acta, 53, 3181 (2008).

31. R. Yang, J. Leisch, P. Strasser, and M. F. Toney, Chem. Mater, 22, 4712 (2010).

32. D. van der Vliet, C. Wang, M. Debe, R. Atanasoski, N. M. Markovic, and V. R. Stamenkovic, Electrochim. Acta, 56, 8695 (2011).

33. I. E. L. Stephens, A. S. Bondarenko, L. Bech, and I. Chorkendorff, ChemCatChem, 4, 341 (2012).

34. V. Stamenkovic, B. S. Mun, K. J. J. Mayrhofer, P. N. Ross, N. M. Markovic, J. Rossmeisl, J. Greeley, and J. K. Nørskov, Angew. Chem. Int. Ed. Engl., 45, 2897 (2006).

35. M. Nesselberger, S. Ashton, J. C. Meier, I. Katsounaros, K. J. J. Mayrhofer, and M. Arenz, J. Am. Chem. Soc., 133, 17428 (2011).

36. F. J. Perez-Alonso, D. N. McCarthy, A. Nierhoff, P. Hernandez-Fernandez, C. Strebel, I. E. L. Stephens, J. H. Nielsen, and I. Chorkendorff, Angew. Chem. Int. Ed. Engl., 51, 4641 (2012).

37. I. Katsounaros, W. B. Schneider, J. C. Meier, U. Benedikt, P. U. Biedermann, A. Cuesta, A. A. Auer, and K. J. J. Mayrhofer, Phys. Chem. Chem. Phys., 15, 8058 (2013).

38. M. Nesselberger, M. Roefzaad, R. F. Hamou, P. U. Biedermann, F. F. Schweinberger, S. Kunz, K. Schloegl, G. K. H. Wiberg, S. Ashton, U. Heiz, K. J. J. Mayrhofer, and M. Arenz, Nat. Mater, 12, 919 (2013).

39. S. Gilman, J. Phys. Chem., 67, 78 (1963).

40. S. Gilman, J. Electroanal. Chem., 7, 382 (1964)

41. S. B. Brummer, J. Phys. Chem., 69, 562 (1965).

42. T. Biegler and R. Woods, J. Electroanal. Chem. Interfacial Electrochem., 20, 73 (1969).

43. T. R. Ralph, G. A. Hards, J. E. Keating, S. A. Campbell, D. P. Wilkinson, M. Davis, J. St-Pierre, and M. C. Johnson, J. Electrochem. Soc,, 144, 3845 (1997).

44. O. V. Cherstiouk, P. A. Simonov, V. I. Zaikovskii, and E. R. Savinova, J. Electroanal. Chem., 554-555, 241 (2003).

45. U. A. Paulus, A. Wokaun, G. G. Scherer, T. J. Schmidt, V. Stamenkovic, N. M. Markovic, and P. N. Ross, Electrochim. Acta, 47, 3787 (2002).

46. U. A. Paulus, A. Wokaun, G. G. Scherer, T. J. Schmidt, V. Stamenkovic, V. Radmilovic, N. M. Markovic, and P. N. Ross, J. Phys. Chem. B, 106, 4181 (2002).

47. I. Takahashi and S. S. Kocha, J. Power Sources, 195, 6312 (2010).

48. S. S. Kocha, J. W. Zack, S. M. Alia, K. C. Neyerlin, and B. S. Pivovar, ECS Trans., 50, 1475 (2012).

49. K. Shinozaki, B. S. Pivovar, and S. S. Kocha, ECS Trans., 58, 15 (2013)

50. Y. Garsany, I. L. Singer, and K. E. Swider-Lyons, J. Electroanal. Chem., 662, 396 (2011).

51. Y. Garsany, O. A. Baturina, K. E. Swider-Lyons, and S. S. Kocha, Anal. Chem., 82, 6321 (2010).

52. S. L. Gojkovicć, S. K. Zecevic, and R. F. Savinell, J. Electrochem. Soc., 145, 3713 (1998).

53. N. Markovic, H. Gasteiger, and P. Ross, J. Electrochem. Soc., 144, 1591 (1997).

54. T. J. Schmidt, U. A. Paulus, H. A. Gasteiger, and R. J. Behm, J. Electroanal. Chem., 508, 41 (2001).

55. P. N. Ross, J. Electrochem. Soc., 126, 67 (1979).

56. N. Markovic and P. N. Ross, J. Electroanal. Chem., 330, 499 (1992).

57. N. Markovic, M. Hanson, G. McDougall, and E. Yeager, J. Electroanal. Chem Interfacial Electrochem., 214, 555 (1986).

58. W. Pell, A. Zolfaghari, and B. Conway, J. Electroanal. Chem., 532, 13 (2002).

59. R. Subbaraman, D. Strmenik, V. Stamenkovic, and N. M. Markovic, J. Phys. Chem. $C, \mathbf{1 1 4}, 8414$ (2010).

60. G. E. Dima, G. L. Beltramo, and M. T. M. Koper, Electrochim. Acta, 50, 4318 (2005).

61. K. Nakata, Y. Kayama, K. Shimazu, A. Yamakata, S. Ye, and M. Osawa, Langmuir, 24, 4358 (2008).

62. E. B. Molodkina, M. R. Ehrenburg, Y. M. Polukarov, A. I. Danilov, J. Souza-Garcia, and J. M. Feliu, Electrochim. Acta, 56, 154 (2010).

63. G. E. Dima, A. C. A. de Vooys, and M. T. M. Koper, J. Electroanal. Chem., 554555, 15 (2003).

64. M. C. P. M. da Cunha, M. Weber, and F. C. Nart, J. Electroanal. Chem., 414, 163 (1996).

65. S. Sugawara, T. Maruyama, Y. Nagahara, S. S. Kocha, K. Shinohara, K. Tsujita, S. Mitsushima, and K. Ota, J. Power Sources, 187, 324 (2009). 
66. A. Berna, V. Climent, and J. Feliu, Electrochem commun, 9, 2789 (2007).

67. O. J. Curnick, B. G. Pollet, and P. M. Mendes, RSC Adv., 2, 8368 (2012).

68. M. Ahmed, D. Morgan, G. A. Attard, E. Wright, D. Thompsett, and J. Sharman, J. Phys. Chem. C, 115, 17020 (2011).

69. A. Damjanovic, A. Dey, and J. O. Bockris, Electrochim. Acta, 11, 791 (1966).

70. J. Maruyama, M. Inaba, K. Katakura, Z. Ogumi, and Z. Takehara, J. Electroanal. Chem., 447, 201 (1998).

71. A. Damjanovic, M. A. Genshaw, and J. O. Bockris, J. Electrochem. Soc., 114, 466 (1967).

72. D. Chu, D. Tryk, D. Gervasio, and E. B. Yeager, J. Electroanal. Chem. Interfacial Electrochem., 272, 277 (1989).

73. A. B. Papandrew, R. W. Atkinson, G. A. Goenaga, S. S. Kocha, J. W. Zack, B. S. Pivovar, and T. A. Zawodzinski, J. Electrochem. Soc., 160, F848 (2013).

74. D. van der Vliet, D. S. Strmcnik, C. Wang, V. R. Stamenkovic, N. M. Markovic, and M. T. M. Koper, J. Electroanal. Chem., 647, 29 (2010).

75. J. Wu and H. Yang, Acc. Chem. Res., 46, 1848 (2013).

76. J. Omura, H. Yano, M. Watanabe, and H. Uchida, Langmuir, 27, 6464 (2011).

77. D. R. Lawson, L. D. Whiteley, C. R. Martin, M. N. Szentirmay, and J. I. Song, J. Electrochem. Soc., 135, 2247 (1988).

78. F. A. Uribe, T. E. Springer, and G. Shimshon, J. Electrochem. Soc., 139, 765 (1992)

79. S. Sugawara, K. Tsujita, S. Mitsushima, K. Shinohara, and K. Ota, Electrocatalysis, 2, 60 (2010).

80. Y. Huang, J. Zhang, A. Kongkanand, F. T. Wagner, J. C. M. Li, and J. Jorne, J. Electrochem. Soc., 161, F10 (2013).

81. Y. Liu, M. Mathias, and J. Zhang, Electrochem. Solid-State Lett., 13, B1 (2010).

82. J. Kim, S. W. Lee, C. Carlton, and Y. Shao-Horn, Electrochem. Solid-State Lett., 14, B110 (2011)

83. Y. Garsany, J. Ge, J. St-Pierre, R. Rocheleau, and K. E. Swider-Lyons, J. Electrochem. Soc., 161, F628 (2014)

84. F. J. Vidal-Iglesias, J. Solla-Gullón, V. Montiel, and A. Aldaz, Electrochem. commun., 15, 42 (2012).

85. B. E. Conway, H. Angerstein-Kozlowska, W. B. A. Sharp, and E. E. Criddle, Anal Chem., 45, 1331 (1973).

86. S. Gottesfeld, I. D. Raistrick, and S. Srinivasan, J. Electrochem. Soc., 134, 1455 (1987).

87. A. Parthasarathy and C. R. Martin, J. Electrochem. Soc., 138, 916 (1991).

88. S. S. Kocha, in Handbook of Fuel Cells - Fundamentals, Technology and Applications, W. Lamm, V. Arnold, and H. A. Gasteiger, Editors, vol. 3, p. 538, John Wiley \& Sons, Ltd, Chichester, UK (2003).

89. E. Higuchi, H. Uchida, and M. Watanabe, J. Electroanal. Chem., 583, 69 (2005).

90. K. J. J. Mayrhofer, B. B. Blizanac, M. Arenz, V. R. Stamenkovic, P. N. Ross, and N. M. Markovic, J. Phys. Chem. B, 109, 14433 (2005).

91. V. S. Murthi, R. C. Urian, and S. Mukerjee, J. Phys. Chem. B, 108, 11011 (2004).

92. C. Wang, M. Chi, D. Li, D. Strmcnik, D. van der Vliet, G. Wang, V. Komanicky, K.-C. Chang, A. P. Paulikas, D. Tripkovic, J. Pearson, K. L. More, N. M. Markovic, and V. R. Stamenkovic, J. Am. Chem. Soc., 133, 14396 (2011).

93. C. Wang, D. Li, M. Chi, J. Pearson, R. B. Rankin, J. Greeley, Z. Duan, G. Wang, D. van der Vliet, K. L. More, N. M. Markovic, and V. R. Stamenkovic, J. Phys. Chem. Lett., 3, 1668 (2012).
94. V. R. Stamenkovic, B. Fowler, B. S. Mun, G. Wang, P. N. Ross, C. A. Lucas, and N. M. Marković, Science, 315, 493 (2007).

95. V. R. Stamenkovic, B. S. Mun, M. Arenz, K. J. J. Mayrhofer, C. A. Lucas, G. Wang, P. N. Ross, and N. M. Markovic, Nat. Mater., 6, 241 (2007).

96. D. F. van der Vliet, C. Wang, D. Tripkovic, D. Strmcnik, X. F. Zhang, M. K. Debe, R. T. Atanasoski, N. M. Markovic, and V. R. Stamenkovic, Nat. Mater, 11, 1051 (2012).

97. A. Zolfaghari, B. E. Conway, and G. Jerkiewicz, Electrochim. Acta, 47, 1173 (2002).

98. J. M. Elliott and J. R. Owen, Phys. Chem. Chem. Phys., 2, 5653 (2000).

99. R. N. Carter, S. S. Kocha, F. Wagner, M. Fay, and H. A. Gasteiger, ECS Trans., 11, 403 (2007).

100. M. Uchimura and S. S. Kocha, ECS Trans., 11, 1215 (2007).

101. S. Jomori, N. Nonoyama, and T. Yoshida, J. Power Sources, 215, 18 (2012).

102. Z. Liu, G. S. Jackson, and B. W. Eichhorn, Angew. Chem. Int. Ed. Engl., 49, 3173 (2010).

103. M. Shao, J. H. Odell, S.-I. Choi, and Y. Xia, Electrochem. commun., 31, 46 (2013).

104. K. Shinozaki, H. Yamada, and Y. Morimoto, J. Electrochem. Soc., 158, B467 (2011).

105. H. A. Gasteiger, N. M. Markovic, and P. N. Ross, J. Phys. Chem., 99, 16757 (1995).

106. H. A. Gasteiger, N. M. Markovic, and P. N. Ross, J. Phys. Chem., 99, 8290 (1995).

107. N. M. Markovic and P. N. Ross, Surf. Sci. Rep., 45, 117 (2002).

108. H.A. Gasteiger, W. Gu, R. Makharia, M. F. Mathias, and B. Sompalli, in Handbook of Fuel Cells - Fundamentals, Technology and Applications, vol. 3, W. Vielstich, A. Lamm, and H. A. Gasteiger, Editors, p. 593, Wiley, Chichester, UK (2003).

109. J. Bett, J. Lundquist, E. Washington, and P. Stonehart, Electrochim. Acta, 18, 343 (1973).

110. S. Mukerjee and S. Srinivasan, J. Electroanal. Chem., 357, 201 (1993).

111. Y. Takasu, N. Ohashi, X.-G. Zhang, Y. Murakami, H. Minagawa, S. Sato, and K. Yahikozawa, Electrochim. Acta, 41, 2595 (1996).

112. A. Damjanovic and P. G. Hudson, J. Electrochem. Soc., 135, 2269 (1988).

113. A. Damjanovic, J. Electrochem. Soc., 138, 2315 (1991).

114. T. Nagai, H. Murata, and Y. Morimoto, ECS Trans., 33, 125 (2010).

115. S. Sugawara, Y. Suzuki, S. Kocha, and K. Shinohara, Electrochemistry, 79, 404 (2011).

116. R. Jinnouchi, K. Kodama, T. Hatanaka, and Y. Morimoto, Phys. Chem. Chem. Phys., 13, 21070 (2011)

117. M. Wakisaka, H. Suzuki, S. Mitsui, H. Uchida, and M. Watanabe, Langmuir, 25, 1897 (2009).

118. H. Imai, K. Izumi, M. Matsumoto, Y. Kubo, K. Kato, and Y. Imai, J. Am. Chem. Soc., 131, 6293 (2009).

119. G. Jerkiewicz, G. Vatankhah, J. Lessard, M. P. Soriaga, and Y.-S. Park, Electrochim. Acta, 49, 1451 (2004)

120. B. E. Conway, B. Barnett, H. Angerstein-Kozlowska, and B. V. Tilak, J. Chem. Phys., 93, 8361 (1990).

121. H. You, D. J. Zurawski, Z. Nagy, and R. M. Yonco, J. Chem. Phys., 100, 4699 (1994).

122. E. L. Redmond, B. P. Setzler, F. M. Alamgir, and T. F. Fuller, Phys. Chem. Chem. Phys., 16, 5301 (2014). 